\title{
André Breton, der französische Surrealismus und die Folgen
}

Nach schwierigem und umkämpftem Beginn konnte einer jener Autoren, deren Werk sich wie das Albert Cohens oder Ernst Jüngers auf einen Großteil des 20. Jahrhunderts erstreckte und von denen man nie recht weiß, in welche Jahrhunderthälfte man sie stecken soll, 1950 in einem Vortrag über den Surrealismus sagen, dieser sei als literarische und künstlerische Bewegung längst kanonisiert. Er habe einen festen Platz innerhalb der Literatur und Kunst des 20. Jahrhunderts eingenommen. Dieser Autor, der dem Surrealismus huldigte, ohne jemals dieser Gruppe angehört zu haben, hieß Julien Gracq, den wir in der Folge kurz aus jenem Vortrag mit dem Titel Le surréalisme et la littérature contemporaine zitieren wollen. Wie Albert Cohen gehört auch Julien Gracq zu jenen Schriftstellern, die einen großen Namen besitzen, aber ein weit größeres Lesepublikum verdienen:

Diese Bewegung, welche die Redakteure der Nouvelles littéraires und der Action française durch ihren blasphemischen und spitzbübischen Anstrich beeindruckte, diese Bewegung, welche sich als eine ständige Ohrfeige für all das verstand, was in der Literatur Karriere macht und seriöse Professionalität ausstrahlt, erhielt am Ende eine Art Konsekration; sie verwandelte sich in ein nationales Gut und wurde fast offiziell, und mehr noch: Sie wurde zu einem angesehenen Exportartikel, der besonders in Amerika mit Genuss konsumiert wird und den die französischen Kulturdienste mittlerweile mit aller Ernsthaftigkeit verbreiten. Breton selbst, der geglaubt hatte, mehr als jeder andere dafür getan zu haben, sich der Literatur als unwürdig zu erweisen, ist heute ein berühmter Dichter, und sogar mehr noch: so etwas wie der Patriarch der französischen Dichtkunst. Diese Art von Kanonisierung, welche die Wendung des letzten Krieges auf eine ironische Weise unterstrich, hat der Surrealismus gewiss nicht gesucht, doch war sie in den Dingen eingeschrieben: Sie bedeutet nur, dass die Masse des Publikums - oder zumindest ein großer Teil davon - endlich seinen Rückstand gegenüber einer Vorläuferbewegung aufgeholt hat und dass dieses Publikum mittlerweile ganz selbstverständlich Sichtweisen akzeptiert, welche ihm vor fünfundzwanzig Jahren höchstens ein Lächeln entlockten. ${ }^{1}$

Die Passage entwirft meisterhaft und mit großer Kenntnis das Portrait einer avantgardistischen Bewegung, die auf Angriff gebürstet war, möglichst keinen Stein auf dem anderen stehen lassen wollte, alle Formen von literarischem Prestige und künstlerischer Konsekration angriff, um schließlich festzustellen (oder feststellen $\mathrm{zu}$ müssen), dass man sie selbst mittlerweile vereinnahmt hatte und als hohes Kulturgut konsumierte. Ja mehr noch: dass man sie auf allen offiziellen Kanälen

1 Gracq, Julien: Le surréalisme et la littérature contemporaine. In (ders.): Euvres complètes. Édition de Bernhild Boie. Paris: Gallimard, „Bibliothèque de la Pléiade“, 1989, Bd. I, S. 1015.

Ә Open Access. (C) 2021 Ottmar Ette, publiziert von De Gruyter. (c) BY-NC-ND Dieses Werk ist lizensiert unter einer Creative Commons Namensnennung - Nicht-kommerziell - Keine Bearbeitung 4.0 International Lizenz. https://doi.org/10.1515/9783110703450-016 


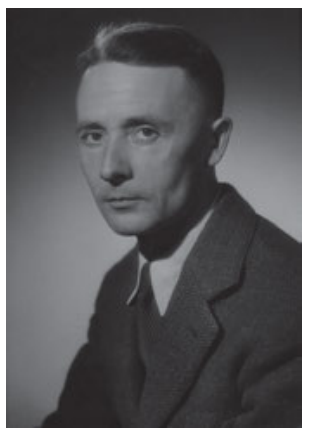

Abb. 75: Julien Gracq (Saint-Florent-le-Vieil bei Angers, 1910 Angers, 2007).

gerade auch im Ausland propagierte und als Teil der maßgeblichen französischen Literatur anpries. Julien Gracq macht hier auf einen spannenden und letztlich entscheidenden Punkt aufmerksam, der für unsere Vorlesung von zentraler Bedeutung ist: auf die Art und Weise nämlich, wie eine radikale, revolutionäre Bewegung, die alles angreift, was in der Kulturwelt eines Landes groß und teuer und geschätzt ist, selbst auf eine höchst offizielle Weise vereinnahmt und angeeignet wird. Letztlich findet sie sich mehr oder minder verwundert selbst in der Rolle des hohen Kulturgutes wieder, ausgestattet mit allen Ehrenbezeugungen der Konsekration.

In der Tat war der französische Surrealismus, der sich zu Beginn keineswegs als Literatur verstand und schlicht auf eine literarische Bewegung reduziert werden wollte, zu einer fast nationalen Institution, ja einem Exportschlager geworden, nach dem man sich im In- und Ausland die Finger leckte. Wie keine andere avantgardistische Bewegung vor ihm sah sich der Surrealismus einer wahren Welle des Kulturkonsums ausgesetzt, welche die Infragestellung der Kunst als die höchste Kunst, die Hinterfragung der Literatur als höchsten Ausdruck der Literatur ansah und massenwirksam propagierte. Die historischen Avantgarden erhielten großen Zulauf und hatten immer größeren Erfolg. Aber wurde das nicht zu ihrem Verderben? Stand ihnen und speziell dem Surrealismus nicht das Schicksal bevor, zu nichts anderem als einer weiteren künstlerischen oder literarischen Bewegung zu werden, zu einem weiteren Ismus, den man wunderbar kunst- und literarhistorisch bearbeiten und vereinnahmen konnte?

Nun, der französische Surrealismus besaß sogar schon eine eigene Geschichte, die von mir bereits erwähnte Histoire du surréalisme, die von Maurice Nadeau im November 1944 abgeschlossen worden war und in dessen „Avertissement“ man gleich zu Beginn lesen konnte:

Eine Geschichte des Surrealismus! Ist der Surrealismus also tot! Dies entspricht nicht unserer Vorstellung. Der surrealistische Geisteszustand, vielleicht müsste man besser sagen: die surrealistische Verhaltensweise ist ewig. Verstanden als eine gewisse Bereit- 
schaft, nicht das Reale zu transzendieren, sondern es zu vertiefen, ein „immer klareres und zugleich immer leidenschaftlicheres Bewusstsein für die sinnliche Welt“ (André Breton), was das Ziel aller Philosophien ist, welche als Gegenstand nicht nur die Bewahrung der Welt haben, so wie sie ist, einen ewig ungestillten Durst im Herzen des Menschen. ${ }^{2}$

Man merkt diesem Vorwort und dem ganzen Vorhaben, eine Geschichte des Surrealismus zu verfassen, deutlich noch die Unsicherheit und zeitliche Nähe zur Bewegung selbst an, die aus jeder Zeile von Maurice Nadeau spricht. Aber die Absicht des Verfassers war es keineswegs, den Surrealismus für tot zu erklären, ausgehend von der Überlegung, dass man eine Geschichte nur dann schreiben könne, wenn sie abgeschlossen vor einem liegt und damit eben tot und passé ist. Ziel war es vielmehr, diese Histoire du surréalisme zu schreiben, während die Geschichte noch in Bewegung und unabgeschlossen ist. Maurice Nadeau wurde damit gleichzeitig zu einem Vorläufer zeitgenössischer Literaturwissenschaft, die schon längst nicht mehr zwischen sich und ihre Forschungsobjekte einen Sicherheitsabstand von mindestens hundert Jahren stellt. Als ich mein Studium der Romanistik in den siebziger Jahren des vergangenen Jahrhunderts begann, war es schon etwas ungeheuer Aktuelles, wenn man in einer Vorlesung von Marcel Proust hörte und etwa $A$ la recherche du temps perdu besprochen wurde - nicht selten versehen mit dem Hinweis, dass man sich dabei aus Gründen mangelnder zeitlicher Distanz gewiss auf unsicherem Terrain bewege.

Damit haben wir jetzt zwei Zeugnisse aus der Endzeit des Zweiten Weltkriegs beziehungsweise der unmittelbaren Nachkriegszeit und zugleich zwei wichtige Belege für die außergewöhnliche Rezeption des (französischen) Surrealismus, die auf sehr unterschiedliche Weise nicht allein in Frankreich um sich greifen konnte. Zum einen haben wir es zu tun mit dem Exportartikel Surrealismus, der wie jede andere literarische und kulturelle Bewegung, Strömung oder Tendenz untersucht, klassifiziert, vermarktet, instrumentalisiert, exportiert und literarhistorisch entschärft werden konnte, ja zum Objekt einer Kulturbürokratie französischer Provenienz avancierte. Zum anderen handelt es sich um ein Zeugnis, welches das Fortleben des Surrealismus behauptet und zugleich die These aufstellt, dass der Surrealismus nicht nur eine literarische oder künstlerische Bewegung oder eine bestimmte Weltsicht, sondern zugleich eine Haltung, Verhaltens- und Seinsweise gegenüber dem Leben und damit auch ewig und unvergänglich sei. Wir sollten diese beiden Blitzlichtaufnahmen des Surrealismus im Kopf behalten, wenn wir uns nun mit der Entstehung dieser herausragenden künstlerisch-literarischen Bewegung auseinandersetzen.

2 Naudeau, Maurice: Histoire du surréalisme (1945). Paris: Seuil 1964, S. 4. 
Denn wir dürfen eines konstatieren: Der Surrealismus verbreitete und setzte sich zunächst in Frankreich, dann in anderen Teilen Europas und der Welt durch; er strahlte auf Lateinamerika, die Karibik und - über die „Négritude“-Bewegung von Aimé Césaire und Léopold Sédar Senghor - auch auf Afrika aus. In Hinblick auf Dauer und Beständigkeit findet sich innerhalb der Avantgarden insgesamt nichts oder doch wenig Vergleichbares. Der Surrealismus ist ganz ohne jeden Zweifel die herausragende literarische, künstlerische, politische und existentielle Bewegung innerhalb der historischen Avantgarden; und er eröffnet zugleich auch das letzte Kapitel innerhalb jener historischen Avantgardebewegung, der wir uns in unserer Vorlesung so aufmerksam und eingehend widmen.

Werfen wir nochmals einen Blick auf die spezifisch literarhistorischen Prozesse und deren Einteilung. Denn angesichts des Erörterten überrascht es nicht, dass Wolfgang Asholt und Walter Fähnders ihre Anthologie von Manifesten und Proklamationen der europäischen Avantgarde in insgesamt vier Kapitel einteilten. Sie gruppierten sie wie: erstens „Der futuristische Aufbruch der Avantgarde (1909 bis 1916)“; zweitens „Zwischen Dada und Revolution (1916 bis 1920)“; drittens „Die Zeit der Ismen (1920 bis 1924)“; und schließlich viertens „Im Zeichen des Surrealismus (1924 bis 1938)“. Dabei wird schon an der Zeitspanne des letzten Teils die besondere Bedeutung des Surrealismus ablesbar, freilich werden aber auch jene spezifischen historischen und politischen Verhältnisse deutlich, welche dieses letzte Kapitel der historischen Avantgarden bestimmten. Vergessen wir bei diesen literarhistorischen Einteilungen auch nicht, dass es sich lediglich um Periodisierungen der europäischen Avantgarden handelt!

Die Tatsache, dass der französische Surrealismus - und in seinem Gefolge der Surrealismus überhaupt - zur beherrschenden Kraft innerhalb der Avantgardebewegungen werden konnte, ist vor allem einem Mann geschuldet, der zu so etwas wie einem Papst des Surrealismus - wie er auch von Abtrünnigen oder Häretikern der Bewegung genannt wurde - geworden war: André Breton. Beschäftigen wir uns also zumindest kurz mit einigen für uns wichtigen Biographemen seines Lebens!

André Breton wurde am 18. Dezember 1896 in Tinchebray (im Département Orne in der Normandie) geboren und starb in Paris am 28. September 1966. Der junge Mann aus der Provinz, der mit seinen Eltern freilich schon früh in die Pariser Region umgezogen war, studierte als Sohn eines Kaufmanns (nach anderen Quellen eines Polizisten) ab 1914 Medizin, mit besonderem Interesse an Psychiatrie, und wurde zum Sanitätsdienst eingezogen. Er las früh die Schriften Sigmund Freuds, die ihn faszinierten und vielfältig poetisch inspirierten. Bald schon brach er sein Medizinstudium ab und machte sich als Schriftsteller selbständig; 1919 gründete er zusammen mit Louis Aragon und Philippe Soupault die dadaistische oder dem Dadaismus doch nahestehende Zeitschrift Littérature. 
Durch den Besuch Freuds 1921 in Wien lernte er unter anderem dessen Traumdeutung anschaulich kennen, was seine eigene Kunst und Lebenslehre maßgeblich beeinflusste: Spuren, Bilder und Begriffe der Psychoanalyse finden sich in allen großen Schriften des französischen Dichters und Theoretikers. Mit Tristan Tzara, der - wie wir schon sahen - von Zürich nach Paris kam, aber vor allem Robert Desnos, Max Ernst oder Benjamin Péret war er dem Unbewussten auf der Spur und machte literarische Experimente mit der „écriture automatique“, dem automatischen Schreiben, das an Versuche Tzaras, mit denen wir uns beschäftigt haben, anschloss und eine zentrale surrealistische Arbeitstechnik darstellte.

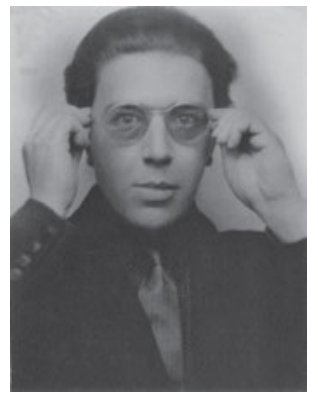

Abb. 76: André Breton (Tinchebray in der Normandie, 1896 Paris, 1966).

Doch die große Zeit André Bretons stand noch bevor: Im Epochenjahr 1924 formulierte er sein Manifest des Surrealismus, mit dem er sich endgültig vom Dadaismus und Tristan Tzara abwandte, um seine eigene ,Lehre` zu begründen. Im selben Jahr wurde dieser Begründer einer Theorie des Surrealismus zum Sprecher einer Gruppe von Autoren, zu denen Louis Aragon, Paul Eluard und viele andere zählten, die sich um die charismatische Gestalt scharten. Mit seinen Freunden und Weggefährten gab er 1924 die neue Zeitschrift La Révolution surréaliste heraus, die zum Organ des französischen Surrealismus wurde. Von 1927 bis 1935 gehörte er der Kommunistischen Partei Frankreichs an, zu der sich ab Mitte der zwanziger Jahre die meisten Surrealisten bekannten, allen voran Louis Aragon. In seinem Zweiten Manifest des Surrealismus unternahm er 1930 den Versuch, den Surrealismus als sozialrevolutionäre Bewegung zu definieren; doch Friktionen mit der Kommunistischen Partei waren von Beginn an sichtbar und verstärkten sich bald.

André Breton tat sich literarisch nicht nur als Dichter, sondern 1928 auch mit seinem Roman Nadja erfolgreich als Romancier hervor und veröffentlichte Schriften zu den Beziehungen zwischen Literatur und Malerei im Zeichen des Surrealismus. Mitte der dreißiger Jahre kam es zum Bruch mit dem Dogmatismus der Kommunistischen Partei Frankreichs wie auch mit dem Stalinismus. Mit Georges Bataille gründete er 1936 die linksrevolutionäre Gruppe „Contre-Atta- 
que“, die jedoch von nur kurzer Dauer war. Breton veranstaltete eine ganze Reihe surrealistischer Ausstellungen und verfasste 1938 zusammen mit Leo Trotzki in Mexiko das Manifest Pour un art révolutionnaire indépendant, das sich für eine internationalistische Revolution in der Kunst stark machte. 1941 flüchtete er aus Frankreich und emigrierte über die Karibik in die USA, wo er erneut fruchtbar mit Marcel Duchamp und Max Ernst zusammenarbeitete und eine Zeitschrift herausgab.

Nach Ende des Zweiten Weltkriegs organisierte er in Paris die offiziell Zweite Internationale Surrealismus-Ausstellung. Der Neuanfang nach der Zeit im Exil erwies sich als schwierig. André Breton war gleichwohl der unbestrittene Haupttheoretiker und Wortführer des Surrealismus, über dessen Orthodoxie er eifersüchtig wachte; er wirkte durch seine Manifeste und Essays, die hier aufzuzählen keinen Sinn macht, unverändert stark auf die Entwicklung von Kunst und Literatur ein. Die Vielzahl an Schriften theoretischen wie dichterischen Zuschnitts bestätigte die bei Breton besonders wirkungsvollen Verbindungen von Theorie, Dichtung und Literatur, die ihn - mit den Worten von Julien Gracq - bald zu einem Patriarchen der französischen Dichtkunst machten. Doch immer wieder suchte er die dichterische Zusammenarbeit in lyrischen Schöpfungen, die er gemeinsam mit Philippe Soupault, Paul Eluard oder René Char unternahm. Bis zu seinem Tode veranstaltete er weitere Ausstellungen surrealistischer Kunst und darf ohne Übertreibung als eigentlicher Papst des Surrealismus bezeichnet werden.

Wir hatten bereits besprochen, dass Tristan Tzara bei seiner Ankunft in Paris auf ein breites Echo stieß und als Zentralfigur des Dadaismus in der französischen Hauptstadt mit offenen Armen aufgenommen wurde. Dada etablierte sich in der Folge in der Kunst- und Literaturszene und wurde $\mathrm{zu}$ einem festen Bestandteil der künstlerischen Welt von Paris, auch wenn die dadaistischen Provokationen immer häufiger ins Leere liefen. $\mathrm{Zu}$ jenen, die Dada begeistert in Paris aufgenommen und Tristan Tzara in seinen Bemühungen wesentlich unterstützt hatten, gehörten unter anderem auch André Breton und Louis Aragon, just jene beiden, die im Grunde zu den entscheidenden Antriebskräften der neuen avantgardistischen Bewegung des Surrealismus werden sollten.

Dabei lässt sich durchaus sagen, dass im Jahr 1924, gleichsam nach der „Zeit der Ismen“ - der Begriff stammt wohl aus der 1925 von El Lissitzky und Hans Arp veröffentlichten Schrift Les Ismes de l'Art / The Ismes of Art -, etwas Neues in der Luft lag. Die Gleichzeitigkeit und Unübersichtlichkeit der Avantgarden war kaum noch zu übertreffen: Es ging nicht mehr - wie Wolfgang Asholt und Walter Fähnders dies formulierten - darum, ob man avantgardistisch sein wollte, sondern höchstens noch darum, was und wo etwas Avantgardistisches stattfinden sollte. Doch der quantitative Höhepunkt des ,Manifestantismus` war bereits überschrit- 
ten, auch wenn in vielen anderen europäischen wie außereuropäischen Ländern die jeweiligen nationalen Eigenentwicklungen die literarische und künstlerische Szene beherrschten. Drohte ein ,Sich-Totlaufen“ der Avantgarden?

Die Unübersichtlichkeiten dieser Jahre sind literarhistorisch schwer in den Griff zu bekommen. An Periodisierungsvorschlägen für den Surrealismus mangelt es nicht. So hat etwa Maurice Nadeau in seiner oben herangezogenen Geschichte des Surrealismus bereits 1944 von einer ersten „heroischen Periode“ des Surrealismus gesprochen und diese auf die Jahre 1923 bis 1925 begrenzt. Bei dieser Periodisierung fällt ins Auge, dass Nadeau - wie ich meine völlig zu Recht - nicht etwa mit dem Jahre 1924 den Surrealismus beginnen lässt, sondern etwas weiter zurückgreift.

Gewiss: Im Herbst 1924 war jenes große ,Doppelpack‘ der Surrealisten publiziert worden, mit dem die Gruppe auf sich aufmerksam machte. Zum einen erschien André Bretons Manifeste du Surréalisme, dem wir uns gleich zuwenden wollen und das André Breton zum Vordenker und zur Leitfigur des Surrealismus machte. Zum anderemn legte man sogleich mit der ersten Nummer der Zeitschrift La Révolution surréaliste nach, die nun zum Organ der neuen Bewegung wurde und an die Stelle der von Breton, Aragon und anderen gegründeten dadaistischen Zeitschrift Littérature trat.

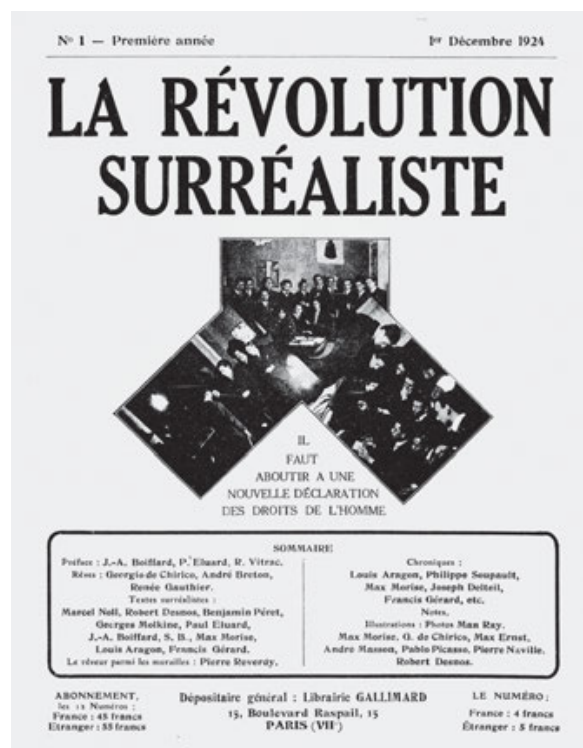

Abb. 77: Titelseite der Erstausgabe der Zeitschrift La Révolution surréaliste, 1924. 
Die Periodisierung Nadeaus macht uns darauf aufmerksam, dass es bereits surrealistische Praktiken und Schreibverfahren gab, bevor das Manifeste du Surréalisme erschien, dass mit anderen Worten die Schreibtechnik der Surrealisten bei weitem ihrer surrealistischen Theorie vorausging. In dieser kulturellen Praxis bildeten bereits das Unbewusste, der Traum, der Zufall und vieles mehr die zentralen Bezugspunkte einer Auffassung von Kunst, welche letztlich auf die Totalität des Menschen abzielte und diese Totalität wiederherzustellen bemüht war. Man könnte deshalb sagen, dass aus surrealistischer Sicht mit dem Erbe der europäischen Aufklärung, mit jenem von Rationalismus und Positivismus, definitiv gebrochen und letztlich auch die Spaltung des abendländischen Menschen in Körper und Geist überwunden werden sollte. Sie sehen, es geht um grundlegende Dinge: Und dies wird - wie wir noch verstehen werden - jenen Ansätzen gar nicht so ferne sein, die sich im Zeichen des Poststrukturalismus und der Postmoderne in der zweiten Hälfte des 20. Jahrhunderts herausbilden sollten. Die Problematik abendländischer Rationalität war in jedem Falle aufgeworfen worden.

Wir sollten die Tatsache nicht übersehen, dass es sich beim Surrealismus nicht einfach um eine weitere avantgardistische Bewegung im Bereich der Literatur handelte. Zahlreich sind die abfälligen Bemerkungen der französischen Surrealisten über die Literatur und deren hochgeschätzte Vertreter. Die surrealistische Bewegung wollte weit über die Literatur hinausgreifen, wollte Politik und Gesellschaft mitgestalten und vor allem dazu beitragen, den Bereich der Kunst in jenen des Lebens zu überführen. Kunst und Leben sollten nicht länger klar voneinander getrennt sein. Der Surrealismus wollte damit jenen Autonomisierungsprozess von Kunst und Literatur zurückdrehen, der sich vor allem im letzten Drittel des 19. Jahrhunderts beschleunigt und Kunst wie Literatur eigene mit einer relativen Autonomie ausgestattete Teilfelder beschert hatte. Diese auf das Leben gerichtete und daher existentielle Dimension des Surrealismus, die in fast all seinen Manifestationen nachvollziehbar präsent ist, gilt es nie aus den Augen zu verlieren.

Der eigentliche Bruch der künftigen Surrealisten mit dem internationalen Dadaismus und Tristan Tzara erfolgte bereits im Jahr 1922. Letztlich, so folgerte Maurice Nadeau, sei dieser Bruch unabwendbar gewesen, denn Tzara hätte sich weiterhin auf die antagonistischen Positionen und Verfahren der anarchistischen (Nach-) Kriegszeit versteift. Andererseits hatten eine Reihe wissenschaftlicher Entdeckungen und Entwicklungen - ebenso in den Natur- wie in den Kulturwissenschaften - wie etwa jene von Albert Einstein oder Sigmund Freud - die dringliche Möglichkeit eröffnet, ein völlig neues Bild der Welt zu entfalten. Maurice Nadeau folgte in seiner Geschichte im Großen und Ganzen den Leitlinien André Bretons. Der Surrealismus knüpfte ohne jeden Zweifel an die Erfahrungen der vorangegangenen Avantgarden und insbesondere an jene des erfolgreichen Dadaismus an, freilich ohne im eigentlichen Sinne nur diese Erfahrungen fortzuschreiben. Es 
ging dem Surrealismus im Kern um innovative Erfahrung und kollektives Experiment: Er verstand sich als Methode der Erzeugung von Wissen und literarischkünstlerischer Erkenntnis, die sich auf Bereiche ausdehnen wollte, welche zuvor nicht zuletzt von den Wissenschaften vernachlässigt worden waren.

Mit Hilfe dieser neuen Ansätze sollten die anarchistischen und vor allem destruktiven Kräfte und Verfahren von Dada überwunden werden, was im Grunde schon seit 1921 mit der Veröffentlichung von Les Champs magnétiques, die André Breton zusammen mit Philippe Soupault schrieb, angedacht war. Diese Magnetischen Felder verstanden sich weniger als ein Stück Literatur, sondern präsentierten sich eher als Versuch und Experiment. Bereits ab 1919, also noch zu Zeiten unbestrittener Vorherrschaft von Dada, wurden die ersten automatischen Texte geschrieben: Die „écriture automatique“ wartete nicht auf die Veröffentlichung des Ersten surrealistischen Manifests. Die angestrebte Erforschung des Traums im Anschluss an, in Konkurrenz zu und in Abweichung von Sigmund Freud führten dazu, dass die künftigen Surrealisten in eine - wie sie es selbst nannten - „époque des sommeils“, in eine gleichsam schläfrige Epoche eintraten. Man Ray hat später die Traumzustände von Robert Desnos, der mit offenen Augen träumte, photographisch festgehalten, wobei André Breton diese Photos dann später in seinen Band Nadja von 1928 aufnahm.

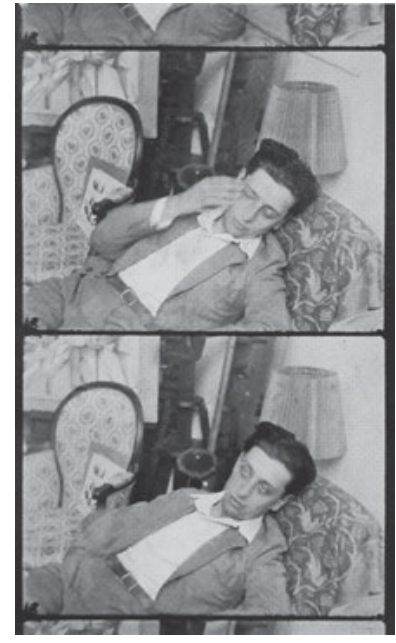

Abb. 78: Man Ray: Robert Desnos im hypnotischen Schlaf, Illustration in André Bretons Nadja, 1928.

Wichtig erscheint mir, dass diese Traumzustände, der Tagtraum, die Problematik des aus der Vernunft wie der Geschichte und der Geschichtsschreibung ausgegrenzten Erscheinung des Traumes, nun in die literarische und künstlerische Produktion ebenso Einzug hielten wie in die Weltsicht und Weltanschauung unter 


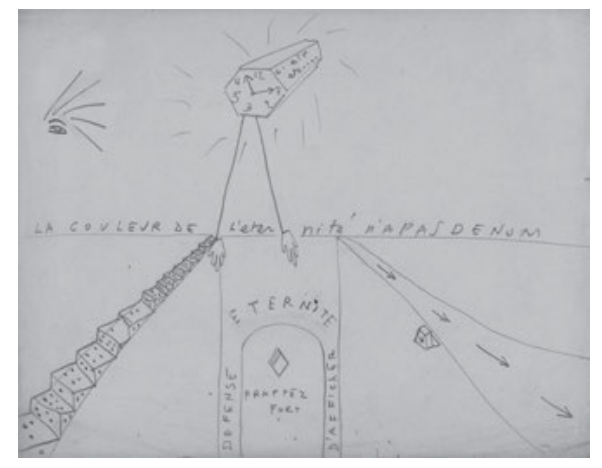

Abb. 79: Von Robert Desnos während des hypnotischen Schlafs angefertigte Zeichnung, 1922.

Einschluss eines grundlegend veränderten Menschenbildes. Eine Problematik, auf welche die Surrealisten selbst hinwiesen. Louis Aragon hat uns eine gelungene Beschreibung dieses neuen Aufbruchs jener Autoren gegeben, die sich in Anschluss an Breton und Soupault nun ihrerseits der Welt der Träume überließen. So heißt es in Une vague de rêve im Jahre 1924:

\begin{abstract}
Was sie beeindruckt, ist eine Macht, die sie an sich nicht kannten, eine unvergleichliche Leichtigkeit, eine Befreiung des Geistes, eine nie gekannte Produktion von Bildern, und der übernatürliche Ton ihrer Schriften. Sie erkennen in allem, was aus ihnen so geboren wird, und ohne zu verspüren, dass sie dafür die Verantwortlichen wären, all das Unleugbare mancher Bücher, mancher Worte, welche sie noch immer bewegen. Sie bemerken plötzlich eine große poetische Einheit, welche von den Prophezeiungen aller Völker bis zu den Illuminations und den Chants de Maldoror reicht. Zwischen den Zeilen lesen sie die unvollständigen Bekenntnisse derer, die eines Tages das System besessen haben: Im Lichte ihrer Entdeckung verliert die Saison en Enfer ihre Rätsel, die Bibel und einige andere Geständnisse des Menschen unter ihrem Bilderwirbel. ${ }^{3}$
\end{abstract}

In diesem Zitat von Louis Aragon wird anschaulich, wie sehr die künftigen Surrealisten noch in der Blütezeit des Dadaismus fasziniert waren von jener Welt, die sie selbst und in sich entdecken konnten, eine Welt, deren Reichtum sie sich nun fast obsessiv aneignen und die sie mit ihren literarischen Mitteln erforschen und darstellen wollten. Die surrealistischen Künstler und Literaten wandten sich dem Unbewussten, dem Irrationalen, dem nicht an die abendländische Vernunft Geketteten zu und ließen sich von dieser Welt jenseits der Ratio freudig und erwartungsvoll in Besitz nehmen. Es muss so etwas wie das Gefühl gewesen sein, die andere, die dunkle, die unsichtbare Seite des Mondes zu erreichen.

3 Aragon, Louis: Une vague de rêves. In (ders.): L'œuvre poétique 1921-1925. Paris: Livre club Diderot 1974, Bd. 2, S. 231 f. 
Immerhin hatte dafür Sigmund Freud durch die wissenschaftliche Modellierung seiner Psychoanalyse seine Fernrohre zur Verfügung gestellt, und doch konnte auch er - so zumindest die Surrealisten - bei weitem nicht alles erschließen und zugänglich machen. Man könnte auch mit Julien Gracq davon sprechen, dass mit diesen Versuchen die andere Seite des Spiegels erreicht werden sollte: all das, was im Grunde so nahe und greifbar, zugleich aber unendlich weit vom rationalen Menschen des Abendlandes entfernt schien. Es ging in der Tat um ein anderes Menschenbild: um eines, das sich für die sogenannten primitiven Völker und Kulturen öffnete, um eines, das von einer Überdrüssigkeit an westlicher Technologie und Problembewältigung gesteuert war. Die Fesseln abendländischer Vernunft sollten gesprengt und das Unbewusste im Menschen nicht nur erforscht, sondern gelebt werden. Das Leben und Erleben dessen, was den künftigen Surrealisten als übernatürlich vorkam, was von weither und dem Wissen all den Kulturen der Völker der Welt zu kommen schien, war urplötzlich mit einer solchen Leichtigkeit zu haben, wie Louis Aragon dies mit großer Verwunderung anschaulich beschrieb. Die Experimente dieser Künstler und Autoren richteten sich in erster Linie auf sich selbst und entdeckten an sich eine ganze Welt des Traumes, der Traumbilder, teils unbewusster Wünsche und Begierden, die in Tagträumen oder in Rauschzuständen an die Oberfläche kamen.

Gleichzeitig macht diese Passage auch deutlich, dass die größtenteils französischen Surrealisten von Beginn an nicht nur fasziniert waren von den Gedichten eines Arthur Rimbaud und dem Vorläufertum der Gesänge des Maldoror eines Conte de Lautréamont, ja bis zu einem gewissen Grad selbst von der Lyrik Stéphane Mallarmés. Vielmehr zeigt sie, dass sie in ihren Versuchen, zum Ursprünglichen und Verborgenen des Menschen vorzudringen, tief beeindruckt sein mussten von den Möglichkeiten, welche ihnen die Überlieferungen, die Kunstgegenstände, die Lebensformen sogenannter ,wilder' Kulturen und ,primitiver Völker bieten konnten. Daher rühren das hohe anthropologische Interesse der Surrealisten, die ethnographischen und völkerkundlichen Versuche, wie Michel Leiris sie etwa in Afrika unternahm.

Einem Michel Leiris war es im Sinne der Surrealisten darum zu tun, an die Lebensvorstellungen und Lebensgewohnheiten von nicht durch die europäische Zivilisation ,verdorbenen` Menschen zu geraten; selbst ein Claude Lévi-Strauss war fasziniert davon, mit jenen Kulturen und Zivilisationen wie den Tupi-Kawahib in Brasilien Kontakt aufzunehmen, die noch niemals zuvor in Verbindung mit der westlichen Zivilisation getreten waren. Den französischen Surrealisten schwebte vor, wie Antonin Artaud oder André Breton jene indigenen Kulturen genauer zu untersuchen, die sich etwa in Mexiko künstlich in bestimmte Schlaf- und Rauschzustände versetzten, um auf diese Weise einen westlichen Zivilisationen bislang weitgehend verborgenen Bereich nun endlich sichtbar und zugänglich zu machen. 
Die Erforschung von Halluzinogenen wurde Programm - und selbstverständlich knüpften sich daran nicht allein persönliche und individuelle Erlebnisformen indigener Transzendenz, sondern auch wissenschaftliche wie wirtschaftliche Interessen, welche sich bald schon dieser Mittel der indigenen Kulturen bedienten. Auch auf diesem Gebiet zeigte sich im weiteren Verlauf des 20. Jahrhunderts rasch, wie leicht diese Praktiken und deren Mittel und Medien von der abendländischen Zivilisation vereinnahmt und einverleibt werden konnten. André Breton war in Mexiko nicht nur bei Leo Trotzki, sondern vor allem auch bei Diego Rivera und Frida Kahlo: Und rasch verselbständigten sich reale wie vorgebliche Erfahrungen mit Halluzinogenen und wurden zu einem Teil der Bemächtigungsstrategien westlicher Künstler*innen und Schriftsteller*innen.

Vor diesem Hintergrund ist der von Wolfgang Asholt und Walter Fähnders zitierte Satz von Walter Benjamin sehr wichtig und zugleich auf transkulturelle Erlebenswelten auszuweiten, dass es ein vordringliches Ziel der Surrealisten gewesen sei, „die Kräfte des Rausches für die Revolution zu gewinnen“. Es ging um eine Verknüpfung der politischen Revolution, für die ein Trotzki weitaus mehr stand als ein Stalin, mit den hypnotischen Kräften indigener Rauschkulturen: Die Befreiung des abendländisch geprägten Menschen aus all seinen Fesseln schien unmittelbar bevorzustehen. Das Ticket für die Schiffsreise zurück nach Europa hatte man freilich immer in der Tasche.

So erscheint es aus heutiger Perspektive als geradezu zwangsläufig, dass sich während der weiteren Entwicklung des Surrealismus einerseits die Erkundung der Traumwelt auch anthropologisch in der Erforschung scheinbar primitiver Völker und Kulturen niederschlug und derartige Forschungen den eigentlich wissenschaftlichen Bereich beflügelten. Andererseits mussten sich auch die außereuropäischen Kulturen und Literaturen hingezogen fühlen zu einer für sie zunächst einmal literarischen und kulturellen Bewegung, die ihnen dabei half, die eigene Welt in Afrika, der Karibik oder in Amerika mit anderen Augen - freilich bisweilen auch mit den Augen des Anderen - neu zu sehen und zu begreifen. Diese interund vor allem transkulturellen Wechselbeziehungen im Zeichen des Surrealismus erwiesen sich auf beiden Seiten des Atlantik als überaus fruchtbar, gleichviel, ob wir an Antonin Artaud in der Sierra Madre oder an Alejo Carpentier in Haiti, an André Breton in Mexiko oder in den Straßen von Paris denken.

Das Element europäisch-abendländischer Logik war von entscheidender Bedeutung für die Entwicklung surrealistischen Denkens, diente es doch als Inbegriff all jener Kräfte, Disziplinierungen und beengenden Traditionsstränge, welche dem Menschen des Abendlandes den Zugang zu seinem tiefsten Inneren und zum Erleben einer Ganzheit der Welt verbaut hatten. Zugang zu und vollständiges Erleben dieser Welt standen im Mittelpunkt surrealistischer Erfahrung des Seins. Denn es ging Breton und seiner Gruppe in der Tat um einen Abschied 
von der Geschichte des Rationalismus und Cartesianismus, lange bevor die dramatische Geschichte dieses Rationalismus - zumindest nach den Analysen von Max Horkheimer und Theodor W. Adorno in ihrer Dialektik der Aufklärung - ihren sinistren Höhepunkt im Terror des Faschismus und des Nationalsozialismus finden sollten.

Zweifellos ist es unter Wissenschaftlern wie Intellektuellen bis heute umstritten, ob diese faschistoiden Entwicklungen mit all ihrer Banalität des Bösen, welche Hannah Arendt an der Geschichte des Eichmann-Prozesses in Jerusalem so wunderbar herausgearbeitet hatte, nun eigentlich die logische Folge einer Dialektik der Aufklärung und damit die Konsequenz auch des europäischen Rationalismus war. Dies behaupteten etwa Jacques Derrida oder Julia Kristeva. Oder war es gerade die Abkehr vom Rationalismus und mehr noch von den Traditionen der Aufklärung, welche all das Unheil des 20. Jahrhunderts heraufführen sollte? Müssen wir diese wichtige Frage auch offen lassen oder einem jeden freistellen, wie er sich in dieser Frage entscheiden mag: Francisco de Goya hatte schon über hundert Jahre zuvor die bis heute gültige und unübertroffen ambivalente Formel für diese Fragestellung gefunden: El sueño de la razón produce monstruos. Ich überlasse es ihrem Scharfsinn und ihrer Neigung, den „sueño“ als „Traum“ oder als „Schlaf“ zu übersetzen und damit zu entscheiden, ob die Ungeheuer nun aus dem Traum der Vernunft oder aus einer abgedankten und folglich schlafenden Vernunft entstanden sein könnten.

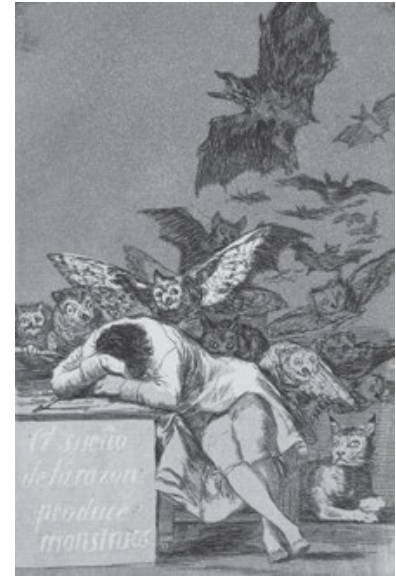

Abb. 80: Francisco de Goya: El sueño de la razón produce monstruos, Radierung, 1799.

Wichtig aber für unsere Vorlesung scheint mir an dieser Stelle, aus dem von André Breton im Herbst des Epochenjahres 1924 veröffentlichten Manifeste du Surréalisme zu zitieren, da genau dort die Frage der zu Grunde liegenden Logik angesprochen wurde: 
Wir leben noch unter der Herrschaft der Logik - und darauf wollte ich hinaus. Aber die logischen Methoden unserer Zeit wenden sich nur noch der Lösung zweitrangiger Probleme zu. Der nach wie vor führende absolute Rationalismus erlaubt lediglich die Berücksichtigung von Fakten, die eng mit unserer Erfahrung verknüpft sind. Die Ziele der Logik hingegen entgehen uns. Unnötig hinzuzufügen, dass auch der logischen Erfahrung Grenzen gezogen wurden. Sie windet sich in einem Käfig, und es wird immer schwieriger, sie entweichen zu lassen. Auch sie stützt sich auf die Tatsache, dass sie unmittelbar nutzbar gemacht werden kann, auch sie wird vom gesunden Menschenverstand bewacht. Unter dem Banner der Zivilisation, unter dem Vorwand des Fortschritts ist es gelungen, alles aus dem Geist zu verbannen, was zu Recht oder Unrecht als Aberglaube, als Hirngespinst gilt, und jede Art der Wahrheitssuche zu verurteilen, die nicht der gebräuchlichen entspricht. Scheinbar durch den größten Zufall nur ist vor kurzem ein Bericht der geistigen Welt wieder ans Licht gehoben worden - meines Erachtens der weitaus wichtigste Bereich -, um den man sich angeblich nicht mehr zu kümmern braucht. Insofern sind wir den Entdeckungen Freuds zu Dank verpflichtet. Auf Grund dieser Entdeckungen bildet sich endlich eine Strömung im Denken heraus, mit deren Hilfe der Erforscher der Menschen seine Untersuchungen weiter zu treiben vermag, da er nun nicht mehr nur summarisch Fakten in Betracht zu ziehen braucht. Die Imagination ist vielleicht im Begriff, wieder in ihre alten Rechte einzutreten. Wenn die Tiefen unseres Geistes seltsame Kräfte bergen, die imstande sind, die der Oberfläche zu mehren oder gar zu besiegen, so haben wir allen Grund, sie einzufangen, sie zuerst einzufangen und danach, wenn nötig, der Kontrolle unserer Vernunft zu unterwerfen. ${ }^{4}$

Lesen wir diese Passagen aus einer Perspektive der Jetztzeit, so ist es erstaunlich, wie aktuell und gegenwartsbezogen diese Überlegungen heute noch immer anmuten. Denn es fällt nicht schwer zu verstehen, dass sich die rationalismuskritische Position des französischen Surrealismus als eine Position erwies, die für den Rest des 20. Jahrhunderts Gültigkeit beanspruchte und wesentliche Standpunkte - insbesondere kulturtheoretischer und mehr noch philosophischer Art der europäischen Neo-Avantgarden gegenüber der Frage der Moderne prägen sollte. Sie trug nicht zuletzt wesentlich dazu bei, dass sich in Frankreich eine andere Haltung gegenüber dem Nationalsozialismus und der Shoah beziehungsweise dem Holocaust entwickelte. In Deutschland ging und geht man mehrheitlich auch noch heute nicht allein im Umfeld der Philosophie von Jürgen Habermas davon aus, dass der Nationalsozialismus gleichsam ein Abrutschen in Irrationalismus, Legenden und Mythen germanischer Urzeiten und eine Verabschiedung aus dem Projekt der Moderne darstellte. Dagegen waren die Positionen in Frankreich rund um den Poststrukturalismus, allen voran die von Jacques Derrida, grundlegend anders gestrickt: Wir haben es auf der anderen Seite des Rheins mit einer geschichtsphilosophisch anders begründeten Position $\mathrm{zu}$ tun, die sich durchaus

4 Breton, André: Manifeste du Surréalisme. In (ders.): Euvres complètes. Hg. von Marguerite Bonnet. Paris Gallimard (Bibliothèque de la Pléiade) 1988, Bd. 1, S. 329. 
auch auf deutsche Philosophietraditionen wie die Dialektik der Aufklärung von Horkheimer und Adorno stützen konnte. Doch waren es gerade die gegenüber dem Rationalismus kritischen Positionen der französischen Surrealisten, welche einer so anderen Einschätzung dessen, was denn Rationalismus und rationalistische Logik sei, Vorschub leisteten.

Die französischen Philosophen und Theoretikerinnen gehen davon aus, dass der Nationalsozialismus insbesondere auch in Hinblick auf die Judenverfolgung und Judenvernichtung eine logische Folge des Rationalismus und seiner Ausgrenzungsmechanismen war, welche in dieser Frage auf eine Spitze getrieben wurden. Die Wannsee-Konferenz stellte eine rational zu bewältigende Aufgabe; und sie konnte auf Millionen von Deutschen zählen, die ihre Zielsetzungen widerstandslos umsetzen würden. Immer wieder zeigt sich an diesen Stellen ein Konzept der Moderne, das an Homogenität und Zentralität ausgerichtet ist, ein Modernekonzept, mit dem wir uns aber noch beschäftigen werden.

Hannah Arendt hat in ihrer Beschreibung des Jerusalemer Eichmann-Prozesses darauf abgehoben, dass der Massenmörder Eichmann ein perfekter Bürokrat war, der sich an Buchführung, an Statistiken, an Durchführungsbestimmungen orientierte und sich auf diese Weise nur indirekt mit den eigentlichen Ermordungen auseinandersetzen musste. Der Massenmörder war ein perfekter Buchhalter. In diesem Sinne hat sie sehr zutreffend von einer „Banalität des Bösen“ gesprochen, die Sie im Übrigen auch bei den heutigen Neonazis beobachten können. Hannah Arendts Analysen halte ich nicht allein mit Blick auf ihre Untersuchung des Totalitarismus, der Vernichtungslager und der Problematik der Macht, sondern auch hinsichtlich dieser „Banalität des Bösen“ für noch immer zielführend und zielgenau, beschreiben sie doch das, was an Vorstellungen des ,Sauberen“ und ,Homogenen“ hinter dem grauenhaften Massenmord an Millionen jüdischer Mitbürger steht. Es ist die moderne rationale Logik ethnischer Säuberungen, wie sie die Geschichte gerade des 20., aber wohl auch des 21. Jahrhunderts immer wieder kennzeichnet. Dass in dieser Banalität des Bösen sehr viel Rationalismus steckt, sehr viel Kontrolle, Statistik und Kalkül, wird man wohl kaum bestreiten können.

Es spricht folglich aus meiner Perspektive vieles für eine Sichtweise des Horrors der Nationalsozialisten nicht als ,Ausrutscher‘ ins Irrationale und Mythische, sondern als Absolut-Setzung ebenso rationaler wie zerstörerischer Kräfte. Gewiss gab es mythische und mythologische Versatzstücke, die auch heute noch wie eh und je durch die Nazi-Literatur geistern. Doch die Grundlagen reichen tiefer und betreffen jene Art von Rationalismus, gegen den die französischen Surrealisten aufbegehrten. Bleiben wir also einen Augenblick noch bei den französischen Poststrukturalisten! Michel Foucault hatte an den Beispielen Sexualität und Wahnsinn - und damit in gewisser Fortführung der Surrealisten - Ausgrenzungsformen auch räumlicher Art (etwa in Form der Irrenanstalten) vorgeführt 
und auf diesbezügliche Normen hingewiesen, welche die Moderne in Europa hervorgebracht hatte. Am Beispiel der Shoah oder des Holocaust kann dementsprechend nicht zuletzt die Frage einer technologischen Vervollkommnung von Ausgrenzungs- und Vernichtungsmechanismen beobachtet werden. Man könnte die Hinwendung der Surrealisten zum Unbewussten und zum Traum durchaus als einen Versuch deuten, aus jener Schiene der Rationalität auszubrechen, die wenige Jahre später in die Vernichtungslager von Auschwitz und Buchenwald führen sollte.

Gewiss: Die sich verhärtenden Positionen haben beiderseits des Rheins dazu geführt, dass zumindest seit Ende der achtziger Jahre des vergangenen Jahrhunderts ein Dialog im Bereich der Philosophie zwischen Deutschland und Frankreich ins Stocken geraten ist, ja zeitweise völlig abgebrochen wurde. Nicht umsonst hat Manfred Frank aus Hintergründen, die ich an dieser Stelle nicht erläutern kann, die aber ein schillerndes Licht auf seine Schlussfolgerungen werfen, hierzu eine klar feindliche Position gegenüber den französischen Poststrukturalisten aufgebaut. Doch scheint mir die Frage noch längst nicht abschließend beantwortet, ob es sich bei der Shoah, der minuziös geplanten Vernichtung der europäischen Juden, um die Folgen eines Schlafs oder Schlafens der Vernunft handelte - einer Verabschiedung aus dem Projekt der Moderne und Rationalität also. Es könnte auch der Traum der Vernunft gewesen sein, der die Ungeheuer und grauenhaften Monster so ungeheuer groß werden ließ und zugleich mit jener berechenbaren Banalität zusammenbrachte, welche in ihrem mörderischen Kalkül von einem ganzen Volk mit seinen vielen Helfershelfern in Europa ins Werk gesetzt werden konnte.

In diesem längeren Zitat aus dem einflussreichen Manifest André Bretons, das in Hinblick auf Umfang und Duktus sehr wohl aus den übrigen Manifesten der historischen Avantgarden heraussticht, wird deutlich, dass sich der Surrealismus in der Tat nicht auf die Dimensionen einer begrenzten literarischen Bewegung reduzieren lässt. Die im Manifest des Surrealismus angesprochenen Fragestellungen sind philosophisch-weltanschaulicher Natur, siedeln sich also zwischen Literatur und Philosophie an und beinhalten eine sehr grundsätzliche Zivilisationskritik, wie sie zuvor in ähnlich fundamentaler Weise eigentlich nur Jean-Jacques Rousseau - auch hier mit einer Rationalismus-feindlichen Spitze vorgetragen hatte.

Jedoch sind diese programmatischen Äußerungen Bretons insgesamt keineswegs Rationalismus-feindlich; sie stellen im Grunde weniger ein Plädoyer für den Traum oder Tagtraum als ein Plädoyer für die Untersuchung des Traumes dar - wieviel Gewicht man diesem Aspekt des Lebens auch immer geben mag. Denn letztlich, so zeigt sich deutlich, ist der wichtige Impuls, den die Forschungen Sigmund Freuds Breton vermittelten, noch bis in dessen eigenes Projekt und 
dessen Zielstellung hinein zu spüren. Denn auch gemäß dieser Passage könnte eines Tages nach einem „capter“ auch ein „soumettre“ folgen, könnten die tiefen Kräfte des Geistes, welche die Tiefenpsychologie Freuds, die ihren Namen nicht zu Unrecht trägt, wiederum durch die Vernunft, folglich von der Ratio her, beherrschbar gemacht werden.

Die Zielvorgabe der Psychoanalyse Sigmund Freuds wird mit Händen greifbar: „Wo Es war, soll Ich werden.“ Und doch ist bei Breton stärker als bei Freud noch - und dies will einiges heißen - die Faszination deutlich, welche von diesem Bereich des Lebens, dem Bereich der Nacht, des Dunklen und nicht unserer Vernunft Unterworfenen, auf die Surrealisten insgesamt ausging. Wir sollten hierbei nicht vergessen, dass die Surrealisten in dieser Hinsicht eine Nachkriegsgeneration darstellen, die also die „Grande Guerre“ zum Teil noch intensiv genug erlebt hatte, um diese Kriegserfahrung in der unmittelbaren Nachkriegszeit in ihre Überlegungen bezüglich des Dunklen, Unheilvollen verstehend miteinzubeziehen. Eros und Thanatos sind für sie wie für Freud gerade auch in ihrem wechselseitigen Zusammenhang von größter Bedeutung. Nicht umsonst lautete die erste der berühmten „enquêtes“ der Surrealisten, ob denn der Selbstmord eine Lösung darstelle.

Die Frage des Todes und dessen Beziehung zum Leben hat also mit der anderen Seite des Mondes, mit der anderen Seite des Spiegels, ganz wesentlich zu tun. Die Frage nach dem Tod ist eine Frage nach dem Leben und dessen Grenzen. Zentral bleibt bei deren Beantwortung das Ausscheren aus einer beengenden, das eigentliche Verstehen des Menschen behindernden Logik, welche den Weg zum Unmittelbaren und Tiefen verstellt. Wir finden im Surrealismus eine wichtige Brücke, die von der Rationalismus-feindlichen deutschen Romantik als Gegenbewegung zur rationalistischen französischen Aufklärungsphilosophie bis hin zur Kritik am Projekt der Moderne im Denken von Derrida, Lyotard oder Baudrillard führt und somit das 19. mit dem ausgehenden 20. Jahrhundert verbindet.

André Breton gehört dabei noch dem Projekt der Moderne an, geht aber an die (im Übrigen auch räumlichen und kulturellen) Grenzen dieses abendländischen Projekts. Diese Tatsache scheint mir bislang noch nicht in aller Deutlichkeit ausgesprochen und vor allem ausgedacht sowie in ihren Konsequenzen entwickelt worden zu sein: Eine Dimension des - wie Louis Aragon formulierte - immensen Schlafes, der sich im Jahr 1922 über der Gruppe der angehenden Surrealisten ausgebreitet hatte. Breton oder Aragon zeichneten auf und dokumentierten, Man Ray hielt vieles auf Photographien fest, Robert Desnos war gar eine Art mediatische Gestalt: Eine neue Welt schien sich hier zu öffnen. Jedoch verstand es André Breton (und neben ihm Louis Aragon), diesen neuen Erfahrungen, Fragen und Praktiken auch die wichtige institutionelle Form zu geben, die unabdingbar war, wollte die Gruppe ihren eigenen Sitz im Leben, in der kulturellen und literarischen 
Szene Frankreichs erobern und verteidigen. Wie gut dies gelang, zeigten ja bereits die literarhistorisch bemerkenswerten Eingangszitate zu Erfolg und Geschichte des Surrealismus.

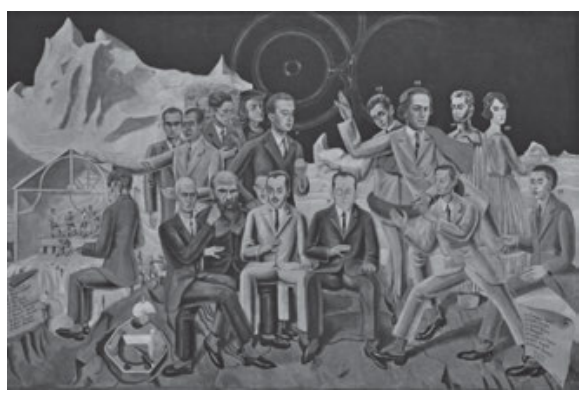

Abb. 81: Max Ernst: Au rendez-vous des amis, Öl auf Leinwand, 1922.

Bevor wir uns kurz dieser institutionellen Geschichte des Surrealismus zuwenden, möchte ich noch auf zwei Aspekte eingehen, welche Breton ebenfalls in seinem Manifest des Surrealismus zum Ausdruck brachte: zum einen die Rolle der Dichtkunst innerhalb dieses neuen Verständnisses von Kunst und Literatur und zum anderen die Herkunft des Begriffs „Surrealismus“ selbst. Bedenken Sie gerade bei letzterer Frage, wie sehr ein Filippo Tommaso Marinetti von jeglicher literarischer Tradition abstrahiert hatte und wie sehr er sich in der Modalität des Bruchs, des Traditionsbrechers, eingerichtet hatte und darstellte. Dies ist bei André Breton - und stärker noch im französischen Surrealismus insgesamt - weitaus weniger der Fall:

Der Mensch fügt und verfügt. Es hängt nur von ihm ab, ob er sich ganz gehören, das heißt, die jeden Tag furchterregende Zahl seiner Begierden im anarchischen Zustand halten will. Die Poesie lehrt es ihn. Sie trägt in sich den vollkommenen Ausgleich für das Elend, das wir ertragen. Sie vermag auch eine ordnende Kraft zu sein, wenn es einem, unter dem Eindruck einer weniger persönlichen Enttäuschung, einfallen sollte, sie tragisch zu nehmen. Die Zeit komme, da sie das Ende des Geldes dekretiert und allein das Brot des Himmels für die Erde bricht!

[...]

$\mathrm{Zu}$ Ehren Guillaume Apollinaires, der gerade gestorben war und der, wie uns schien, sich mehrmals einer solchen Übung unterzogen hatte - ohne dafür allerdings die üblichen literarischen Möglichkeiten aufzugeben - bezeichneten Soupault und ich diese neue Form des reinen Ausdrucks mit dem Namen SURREALISMUS und beeilten uns, was wir an Erkenntnissen gewonnen hatten, unseren Freunden zugänglich zu machen. Ich glaube, dass ich heute nicht mehr auf dieses Wort einzugehen brauche und dass die Auffassung, die wir davon haben, im großen Ganzen das Apollinaire'sche Verständnis desselben verdrängt hat. Zweifellos hätten wir mit noch größerer Berechtigung das Wort SUPERNATURALISMUS übernehmen können, das Gérard de Nerval in der Widmung zu seinen Töchtern der Flammen verwendet hat. Es scheint, als sei Nerval der Geist, auf den wir uns berufen, aufs 
wundervollste zu eigen gewesen, während Apollinaire noch unvollkommen erst über die Vokabel Surrealismus verfügte, unfähig, eine für uns verbindliche theoretische Betrachtung daran zu knüpfen. ${ }^{5}$

Der Beginn des Zitats gibt sich zunächst als Verballhornung eines französischen Sprichworts zu erkennen. Es lautet eigentlich: „L'homme propose et Dieu dispose.“ Die Tatsache, dass hier Gott aus dem Breton'schen Sprichwort, durchsichtig für jeden Franzosen, verschwunden ist, verweist eklatant auf die Tatsache, dass jenseits jeder Transzendenz nun der Mensch selbst die Dinge in die Hand genommen hat. Angesichts der wiederum sehr männerbetonten Position Bretons könnte man sogar formulieren, dass der Mann selbst an die Stelle Gottes getreten ist. Wir verstehen jetzt vielleicht besser, warum Julien Gracq in unserem Eingangszitat vom blasphemischen Grundzug des Surrealismus sprach.

Übrigens haben die Surrealisten sehr gerne auf französische Sprichwörter zurückgegriffen, um ihnen durch leichte Veränderungen und Varianten neue Seiten abzugewinnen. So gingen auch die problematischen Beziehungen vieler Surrealisten zu ihren Müttern ein in die etwas heimtückisch vorgenommene Modifikation des Sprichworts, dass man die Butter jung schlagen müsse, indem man nun - auf Deutsch geht das ebenfalls prima - statt der Butter die Mutter schlägt: „Il faut battre sa mère pendant qu'elle est jeune.“ So schnell geht das! Und schon wird eine ganz andere Dimension von Wirklichkeit sichtbar. Auf die Dimension des Ludischen und vor allem des Sprachspiels bei den französischen Surrealisten komme ich noch zurück. Es besteht eine unübersehbare Verbindung, die vom Surrealismus her - nicht umsonst war Raymond Queneau einer ihrer Vertreter zwischen dem Humor und den Sprachspielen eines Alfred Jarry und den Oulipisten, also den Vertretern des Ouvroir de littérature potentielle, vermittelte. Dieser Sprachwitz ist eine wichtige Dimension surrealistischer Spracharbeit, da sie im Vertrauten plötzlich das Irreale oder Alogische und Akausale aufscheinen lässt.

Die Poesie, die Dichtkunst wird im Manifest des Surrealismus als Möglichkeit der Erfahrung und des erlebenden Umgangs mit den Begierden und dem eigenen Begehren dargestellt und hervorgehoben. Sie ist überdies in der Lage, über das Elend der Welt hinwegzutrösten, eine deutlich kompensatorische Funktion also, die gesamtgesellschaftlich betrachtet nicht ganz ungefährlich scheint und welche die Surrealisten später klar korrigierten. Die Lyrik erscheint in erster Linie als ordnende Kraft: Nichts ist mehr von der zerstörerischen, anarchistischen Kraft des Dadaismus Tristan Tzaras oder auch der Parole in libertà von Marinetti zu spüren.

5 Breton, André: Manifeste du Surréalisme, S. 330. 
Die Poesie besitzt das Vermögen, die Wirklichkeit neu, anders und aufregend zu gestalten und dank ihrer Kräfte als neue Schöpfung demiurgisch zu gestalten.

An dieser Stelle seines Manifests brachte André Breton vor allem eine gesellschafts- und zivilisationskritische Dimension in die surrealistische Weltsicht mit ein. Denn zugleich wird das Ende einer Epoche beschworen, die vom Geld regiert wurde und von vorwiegend ökonomischen Kriterien beherrscht war. In der Tat hat Breton diese Abwertung des Geldes und der Arbeit mehrfach, übrigens auch in Nadja, beschworen. Die Abwertung und Abkehr vom Geld, vom beherrschenden Finanzmarkt, von den der dominanten bürgerlichen Gesellschaft zu Grunde liegenden kapitalistischen Verhältnissen, freilich nicht die Abwertung der Arbeit, sollte schließlich den Weg zum Eintritt mehrerer führender Mitglieder der Surrealisten in die Kommunistische Partei Frankreichs ebnen. Eine Zeit der Zusammenarbeit zwischen Surrealismus und Kommunistischer Partei begann, die sich grob von 1927 bis 1935 erstreckte. Es war freilich ein Honey-Moon ohne nachfolgende feste Bindung.

Der zweite Teil des obigen Zitats hob darauf ab, dass André Breton gemeinsam mit Philippe Soupault die Benennung des Surrealismus gewählt hatte, dass also die Namensgebung ein quasi kollektiver Prozess war, der an eine gemeinsame, überindividuelle literarische und kulturelle Praxis zurückgebunden blieb. Gleichzeitig machte Breton auf zwei freilich von ihm sogleich relativierte Bezugspunkte aufmerksam: zum einen auf Guillaume Apollinaire, der in der Tat, was hier ein wenig verklausuliert ausgedrückt wird, den Begriff des Surrealismus bereits verwendete, aber keine dem Begriff zu Grunde liegende Theorie geschaffen habe. Zum anderen wird Gérard de Nerval erwähnt, der große romantische Dichter der Nacht, der ebenfalls einen wichtigen literarischen Bezugspunkt für die Surrealisten darstellte und von ihnen wie der Conte de Lautréamont als Vorläufer betrachtet wurde.

Überhaupt sind bereits im Manifest des Surrealismus die Bezüge und Traditionslinien zu anderen Autoren präsent, teilweise freilich in ironischer Brechung. So heißt es einige Seiten weiter, dass auch andere Dichter und Schriftsteller bereits Surrealisten gewesen seien. Ich möchte Ihnen dem Manifest folgend einige davon nennen und mit den entsprechend von den Surrealisten geschätzten Werten ausstatten: Swift war surrealistisch in der Bosheit, Sade im Sadismus, Chateaubriand im Exotismus, Constant in der Politik, Hugo wenn er nicht dumm war, Poe im Abenteuer, Baudelaire in der Moral, Rimbaud in der Lebenspraxis, Mallarmé im Geständnis, Jarry im Absinth, Vaché in mir, Reverdy bei sich zuhause, Saint-John Perse in der Distanz und Roussel in der Anekdote.

So ergeben sich schon im Manifest des Surrealismus zahlreiche Beziehungen vor allem zur französischen oder doch französischsprachigen Literatur: für die Surrealisten ist die Welt der Literatur ebenso eindeutig wie selbstverständlich 
,frankozentrisch'. Es handelt sich dabei um intertextuelle Beziehungen, welche die diskursiven Traditionen der Surrealisten literarisch fundieren und sichern; gleichzeitig verankern sie die Surrealisten innerhalb der eigenen nationalen Kulturtradition. Dies scheint mir gerade kein Hinweis auf eine unvermittelte Ästhetik des Bruchs, wie von Peter Bürger behauptet, und zugleich ein wichtiger Aspekt zu sein, welcher zu einem späteren Zeitpunkt der französischen Kulturbürokratie die Mittel an die Hand gab, den Surrealismus als höchst erfolgreiches Exportgut und weithin sichtbares Aushängeschild französischer Kultur zu vereinnahmen und zu vermarkten.

Bis Juni 1924 war die Zeitschrift Littérature das Sprachrohr jener jungen Literaten und Künstler gewesen, die sich zunächst im Umfeld von Dada gruppiert hatten und dann zunehmend eigene Wege zu gehen versuchten. Innerhalb dieser Gruppe aber setzte sich zunehmend André Breton durch, der bald schon folgen wir Maurice Nadeau - ebenso durch seine theoretische Überlegenheit, die sich insbesondere auch in seinen ,methodologischen' Texten dokumentieren lässt, wie durch sein persönliches Charisma die Leitung dieser Gruppe übernahm. Mit seinem weithin sichtbaren Auftreten vermochte er es, diese Künstler und Literaten zu einer in der Folge in jeder Hinsicht schlagkräftigen Truppe umzubilden.

Die Tatsache, dass nun als publizistisches Sprachrohr La Révolution surréaliste herausgebracht wurde, signalisierte den sehr starken und in der Folge zunehmend wachsenden Gruppendruck sowie die Präsenz des Surralismus als kompakte Bewegung unter der Führung von André Breton. Erneut entstand auf diese Weise eine avantgardistische Bewegung, die sich - wie im Falle des Futurismus um Marinetti oder des Dadaismus um Tzara - um die unbestrittene, männliche Leitfigur Breton gruppierte. Es ist sicherlich nicht übertrieben zu sagen, dass ohne André Breton der Surrealismus niemals ein so langes und nachhaltiges, vielfältige Einflüsse erzeugendes kulturelles Leben und Nachleben gehabt hätte. So aber entging er dem voraussehbaren Schicksal der meisten historischen Avantgarden, nach einem eklatanten Auftritt mit viel Lärm und Turbulenzen ein eher ephemeres künstlerisch-literarisches Dasein zu fristen.

André Breton jedoch gelang es, in den verschiedensten Machtkämpfen innerhalb des literarischen und künstlerischen Feldes sowie vor allem auch nach innen die Oberhand $\mathrm{zu}$ behalten und trotz vieler Schwierigkeiten die Surrealisten in ihrer Schlagkraft als Gruppe und Truppe noch zu stärken. Der Verfasser des Gründungsmanifests des Surrealismus schreckte nicht davor zurück, ihm missliebige Surrealisten, die ihm nicht in allen Punkten folgen wollten, kurzerhand vor die Tür zu setzen oder - wie man auch sagen könnte - zu exkommunizieren oder aus der ,Surrealistischen Partei“ auszuschließen. Denn die historischen Avantgarden hatten nicht umsonst eine dem Militärischen entlehnte Metaphorik verwendet. 
André Breton übernahm sehr wohl Formen und vor allem Normen jener Partei, die sich als legitime Nachfolgerin jener Gruppen und Ideologien verstand, die wie wir sahen - bereits im 19. Jahrhundert als politische Avantgarde wahrgenommen wurden. Der Schulterschluss mit der KP Frankreichs lag nahe.

Die Berührungen der Avantgarde des künstlerisch-ästhetischen Bereichs mit der politischen Avantgarde verliefen keineswegs reibungslos. Sie bildeten aber das vielleicht spannendste Experiment auf dem Gebiet der Überschneidungen von politischem und künstlerischem wie literarischem Teilfeld, ein Experiment, das trotz vieler Spannungen und auch Zurückweisungen durch die Genossen der Kommunistischen Partei Frankreichs zwischen 1927 und 1935 Bestand hatte und für einige Surrealisten wie Louis Aragon noch länger hielt. Breton selbst war freilich der Auffassung, dass sich der Surrealismus zwar - so der Titel seiner zweiten Zeitschrift, die die zweite große Phase des Surrealismus einleitete - im Dienste der Revolution sah: Le surréalisme au service de la révolution hieß es nicht umsonst. Doch glaubte er vor allem, dass der Ansatz der Kommunistischen Partei, die nach dem Materiellen schielte, viel zu beschränkt sei, um eine wirkliche Revolution durchzuführen. Breton sah den Primat der Kunst und insbesondere der Poesie, um eine vollständige Welt zu erschaffen, in welcher sich der Mensch frei von jeder Ausbeutung mit all seinen Dimensionen des Lebens entfalten konnte.

Dass der Surrealismus letztlich nicht zu einer fundamentalen Revolution führte, sondern vielmehr hinsichtlich seiner Rezeption zu eben dem wurde, was er eigentlich nicht sein wollte, nämlich eine ästhetische Richtung in Literatur und Kunst, stand auf einem anderen Blatt. Freilich hing dieses Schicksal mit der oben geschilderten Ausgangssituation zusammen. Ich würde mithin keineswegs von einem ,Scheitern“ des Surrealismus sprechen, denn es handelte sich fraglos um die langlebigste avantgardistische Bewegung mit der höchsten Breitenwirkung, welche irgendeine Avantgarde jemals erzielte. Die Revolution, die Breton anzielte, sollte alle Bereiche des Menschen erfassen, vor allem aber jene Lebensbereiche, welche bislang noch niemals systematisch in das Konzept einer Revolution miteinbezogen worden waren. Die von ihm intendierte Umwälzung aller Dinge betraf gerade die Psyche, das Seelenleben, die verborgene Seite des Menschen. Auch auf diesem Gebiet konnte der Surrealismus durchaus Neues vermelden.

Mit Sigmund Freuds Arbeiten und der Ausgestaltung der Psychoanalyse war eine neue, wissenschaftlich fundierte Methode entstanden, die es erlaubte, zumindest einen Teil dieser unbekannten Welt des Menschen zugänglich zu machen und die Tür aufzustoßen zur Lektüre des Unbewussten, das gleichsam im Zentrum des sich herauskristallisierenden Freud'schen Modells von Ich, Es und Über-Ich stand. Wie sehr Breton auch immer die Psychoanalyse in der Folge kritisieren mochte, so tief hatte ihn doch Freuds Versuch geprägt, eine wesentliche Tiefenschicht der menschlichen Psyche zu eröffnen und der Analyse zugänglich 
zu machen. Die wesentlichen Bände des Tiefenpsychologen waren damals bereits ins Französische übersetzt, und noch bevor Breton mit Freud in Wien persönlich zusammentraf, hatte er sich mit dessen Ansichten und Analysen beschäftigt.

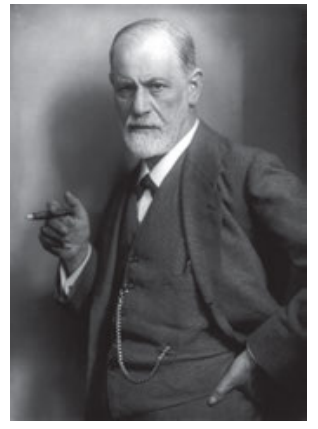

Abb. 82: Sigmund Freud (Freiberg in Mähren, 1856 - London, 1939).

André Breton war fasziniert von Freuds Interpretationen der Traumberichte und mehr noch von der Bedeutung, die von Freud und seinen Kollegen dem Traum zugewiesen wurde. Diese Deutungen waren für André Breton sehr wichtige Ausgangspunkte für die eigene Schöpfung, für die eigene künstlerisch-literarische Arbeit, die aus Freuds Traumdeutung wichtige Anregungen empfing. Ich möchte Ihnen daher zumindest einen kurzen Einblick in Sigmund Freuds Psychoanalyse anhand eines Buches geben, das vor 120 Jahren - also genau mit dem Beginn des neuen Jahrhunderts - erschien und das die Traumdeutung durch die Tiefenpsychologie, aber auch durch Kunst und Literatur bis heute anhaltend revolutionieren sollte. Man darf wohl ungestraft behaupten, dass es bei der Darstellung des Traumes und der Traumsymbolik gerade in Kunst und Literatur eine Zeit vor und eine ganz andere nach Freud gab. Die Wirkung der Psychoanalyse auf Literatur und Kunst kann schlechterdings nicht überschätzt werden!

Sigmund Freuds Die Traumdeutung aus dem Epochenjahr 1900 ging von der Bedeutsamkeit, der Relevanz jener Erscheinungen aus, denen die moderne europäische Gesellschaft des 19. Jahrhunderts im Gegensatz zu den unterschiedlichsten Kulturen und Zivilisationen der Welt, in welchen die Traumdeutung immer eine wichtige Rolle gespielt hatte, keine große Bedeutung mehr beimaß. Für Sigmund Freud aber war der Traum im Kern eine Wunscherfüllung, stand damit in einer direkten Beziehung zur psychischen Wunschwelt und zu dem, was er als das Unbewusste bezeichnete, in welchem er der Triebwelt des Es im psychischen Apparat eine große Bedeutung zuwies.

Dabei lagen die Symbole des Traumes nicht einfach leicht lesbar vor unseren Augen oder denen des Psychoanalytikers. Denn der Traum ermöglicht uns den Zugang zu seinen Inhalten nicht auf direkte Weise, sondern kodiert, ent- und ver- 
stellt sie, zensiert die Bilder, Worte und die Erinnerung an den Traum: Es bedarf einer professionellen Entzifferung. Die Psychoanalyse präsentierte und etablierte sich als Wissenschaft und Methode, einen Zugang zu diesem verschütteten und kodierten Eingang unseres Unbewussten wiederherzustellen. Im Zentrum dieser Methode stand Freuds Auffassung der Traumarbeit, die grundlegende Begriffe und Prozesse beinhaltete, welche Sie sicherlich kennen: Verschiebung, Verdichtung, Verdrängung. Wir sind gar nicht so weit von der Arbeit von Schriftsteller`innen und Künstler^innen entfernt.

In diesen Bereich gehört auch die besondere Bedeutung, die Freud der Sprache zumaß und die später ein Jacques Lacan in seiner Version der Psychoanalyse mit den Ergebnissen der in Entstehung begriffenen strukturalistischen Sprachanalyse verband, kurz gesagt: von der These ausgehend, dass das Unbewusste sprachlich strukturiert sei. Hierher gehören Phänomene wie der Versprecher, der Lapsus, der nicht von ungefähr Freuds Namen trägt. Ein Beispiel? Vor Jahren kam im Radio die Nachricht vom Rücktritt Altbundeskanzler Kohls vom Posten des Ehrenvorsitzenden der CDU. Die Nachricht, welche Helmut Kohl verbreiten ließ, war relativ schlicht, sprachlich aber nicht uninteressant. Denn dort war mit Blick auf die sogenannte „Spendenaffäre“ die Rede davon, er könne nicht „das Versprechen brechen“, das er hohen Persönlichkeiten gegeben habe, ihre Namen nicht preiszugeben.

Arme Nachrichtensprecher, die derartige Formulierungen lesen müssen! Wie wohl ihre eigenen Wunschvorstellungen aussehen mögen? Jedenfalls sprach der Nachrichtensprecher, dem ich aufmerksam lauschte, nicht davon, ein ,Versprechen zu brechen“, sondern ein „Verbrechen zu sprechen“. Das ist, finde ich, ein recht hübsches Beispiel für einen sogenannten „Freud'schen Versprecher“. Es ist nun an Ihnen zu überlegen, ob diese Formulierungen und ihre Umstellungen und Verstellungen uns einen Zugang zum Unbewussten und den Wunschvorstellungen des armen Nachrichtensprechers gewähren oder zum Unbewussten des Altbundeskanzlers, der sein Geheimnis freilich mit ins Grab nahm. Seine späte Witwe dürfte jedenfalls aus seinen Tagebüchern und Mitschriften längst alle Hinweise getilgt haben, welche von den verbrecherischen Namen der Spender sprechen.

Doch nicht alles im Traum hat mit Versprechen, Versprechern und Verbrechern zu tun. Träume sind überdeterminierte Gebilde, die mit einer Wunscherfüllung in Verbindung stehen, welche uns Rückschlüsse zulässt auf den Träumenden und Sprechenden selbst. Schauen wir einmal in Freuds Traumdeutung unter dem Unterkapitel „Wunscherfüllung“ genauer nach!

Eine besondere Bedeutung wies Freud schon früh dem sogenannten Tagesrest zu, ein Aspekt, der André Breton besonders interessierte. Das entsprechende oder versprechende - Zitat lautet: 


\begin{abstract}
Wenn wir auch die Bedeutung der Tagesreste für den Traum durch die vorstehenden Bemerkungen eingeschränkt haben, so verlohnt es doch der Mühe, ihnen noch einige Aufmerksamkeit zu schenken. Sie müssen doch ein notwendiges Ingrediens der Traumbildung sein, wenn uns die Erfahrung mit der Tatsache überraschen kann, dass jeder Traum eine Anknüpfung an einen rezenten Tageseindruck, oft der gleichgültigsten Art, mit in seinem Inhalt erkennen lässt. Die Notwendigkeit für diesen Zusatz zur Traummischung vermochten wir noch nicht einzusehen. Sie ergibt sich auch nur, wenn man an der Rolle des unbewussten Wunsches festhält und dann die Neurosenpsychologie um Auskunft befragt. Aus dieser erfährt man, dass die unbewusste Vorstellung als solche überhaupt unfähig ist, ins vorbewusste einzutreten, und dass sie dort nur eine Wirkung zu äußern vermag, indem sie sich mit einer harmlosen, dem Vorbewußten bereits angehörigen Vorstellung in Verbindung setzt, auf sie ihre Intensität überträgt und sich durch sie decken lässt. Es ist dies die Tatsache der Übertragung, welche für so viele auffällige Vorfälle im Seelenleben der Neurotiker die Aufklärung enthält. [...]

Wir sehen so, dass die Tagesreste, denen wir die indifferenten Eindrücke jetzt zurechnen dürfen, nicht nur vom Unbewussten etwas entlehnen, wenn sie an der Traumbildung Anteil gewinnen, nämlich die Triebkraft, über die der verdrängte Wunsch verfügt, sondern dass sie auch dem Unbewußten etwas Unentbehrliches bieten, die notwendige Anheftung zur Übertragung. ${ }^{6}$
\end{abstract}

In diesen Überlegungen des Begründers der Psychoanalyse wird auch den unscheinbarsten Elementen, die scheinbar bedeutungslos sind, eine große Bedeutung zugewiesen. Nichts erscheint bedeutungslos, alles kann semantisch aufgeladen und zu einer Spur werden, die von der Oberfläche in die Tiefe, vom Manifesten zum Latenten führt. Alles, auch das zufälligste Detail, lässt sich, so unbedeutend es auch erst erscheinen mag, als Element begreifen, das uns Wege $\mathrm{zu}$ unserem Unbewussten aufzeigt, wenn wir es nämlich überdeterminieren, ihm also eine Verschiedenheit an Deutungsmöglichkeiten geben. Wenn wir dies literaturwissenschaftlich umformulieren wollten, hieße dies, jedem Element eine eigene Polysemie, eine Vieldeutigkeit einzuräumen, welche es uns erlaubt, auch das zufälligste Element in verschiedene Bedeutungshorizonte einzuordnen und auf unterschiedlichste Isotopien zu beziehen, innerhalb derer es plötzlich Sinn ergibt. Und mehr noch: Es sind gerade diese zufälligen Elemente, die uns den Weg zu den Tiefen jenseits des Vorbewussten zeigen und unser Unbewusstes zu dekodieren und zu lesen ermöglichen.

An dieser Stelle unserer Vorlesung können wir keine präzise Analyse der Rezeption der Freud'schen Psychoanalyse im Allgemeinen, der Traumdeutung im Besonderen liefern. Sie würde uns jedoch durchaus erklären, warum wir seit dem französischen Surrealismus in der Tat einen Sonderweg Frankreichs hinsichtlich

6 Freud, Sigmund: Die Traumdeutung - Über den Traum. Grafrath: Boer 2018, S. 536-538. 
der Psychoanalyse erkennen können, deren sicherlich berühmteste Vertreter neben vielen anderen - Jacques Lacan, Georges Bataille und Gaston Bachelard waren. Dennoch bleibt festzuhalten, dass für Breton und die Surrealisten die Psychoanalyse und ihre Symboliken von größter Bedeutung für ihre Schöpfungen waren. Da sich die Auswirkungen und Folgen des Surrealismus bis weit in die zweite Hälfte des 20. Jahrhunderts erstreckten, kann die Relevanz dieser Bewegung für die Entwicklungen gerade auch in der zweiten Hälfte des vergangenen Jahrhunderts im Spannungsfeld von Moderne und Postmoderne nur schwerlich überschätzt werden.

Für André Breton und die Mitglieder seiner Gruppe gab es in der surrealistischen Methodenlehre zwei bevorzugte Verfahren: erstens den „Traumbericht“ und zweitens das „automatische Schreiben“, von dem wir schon mehrfach hörten. Beide Verfahren finden sich bereits in den frühesten surrealistischen Texten, etwa in den zusammen mit Philippe Soupault von André Breton verfassten und 1920 erschienenen Champs magnétiques. Auch erscheinen sie selbstverständlich im Manifeste du Surréalisme, das wir uns gerade in seinen ludischen Aspekten etwas näher angesehen haben. Sie finden sich aber auch in einem vielleicht besonders attraktiven literarischen Kontext, einem der großen und erfolgreichen Bände des Surrealismus, Bretons im Jahr 1928 erschienenen Experimentaltext Nadja.

Ich will Ihnen gleich die gesamte Struktur dieses Textes näherbringen, möchte an dieser Stelle aber einen Einstig wählen, der just die von Sigmund Freud quasi ererbte Dimension explizit aufgreift und auch theoretisch vom Boden des Surrealismus her plausibel macht. Wir befinden uns gegen Ende des ersten Teiles von Nadja, und das Erzähler-Ich - viele sagen schlicht und reichlich irreführend André Breton - kommt auf Problematik und Bedeutung des Traumes zu sprechen:

Da die Produktion von Traumbildern immer zumindest von diesem doppelten Spiel der Spiegel abhängt, so findet sich darin der Hinweis auf die sehr spezielle und zweifellos besonders aufdeckende, im Freud'schen Sinne im höchsten Maße „überdeterminierende“ Rolle, welche gewisse starke Eindrücke zu spielen aufgerufen sind, die in keiner Weise von einer Moralität angesteckt werden können und im Traum wirklich als ,jenseits von Gut und Böse“ und in der Folge in dem, was man dem Traum sehr verkürzend als Realität entgegenstellt, empfunden werden. ${ }^{7}$

In dieser etwas verklausulierten Passage wird nicht allein auf die enorme Bedeutung zumindest auf den ersten Blick völlig drittrangiger Elemente hingewiesen, welche in den Traum Eingang finden, sondern vor allem darauf aufmerksam gemacht, dass die Produktion von Traumbildern von einem doppelten Spiel von

7 Breton, André: Nadja. Paris: Gallimard 2007, S. 42. 
Spiegeln abhängig ist. Damit visiert Breton die Vorstellung an, dass nicht nur ein Spiegel im Sinne des Stendhal'schen Realismus über Land gefahren wird, um die krude Realität außerhalb der Kutsche auf den Straßen und in den Straßengräben abzuspiegeln, sondern dass sich die Spiegelungen gleichsam zwischen den Spiegeln perpetuieren und bis in alle Unendlichkeit wechselseitig weiterspiegeln. Dies ist für den Realitätsbegriff des Surrealismus ungeheuer wichtig; denn damit werden die Übergänge zwischen Imagination und Wirklichkeit oder, wie es hier heißt, zwischen Traum und Realität mehr als fließend. Denn auf diese Weise wird auch der Traum zu einer Realität, die im Spiel der Spiegel dieselben Ansprüche geltend machen darf wie eine Realität, welche sozusagen photographisch von der außersprachlichen Wirklichkeit erzeugt wird.

Wir sollten nicht vergessen, dass wir uns zu Beginn unserer Vorlesung bei Maurice Blanchot und seinem Le livre à venir mit diesem Spiel der sich spiegelnden Spiegel beschäftigt haben. Dabei haben wir verstanden, in welch hohem Maße diese Metaphorologie der sich spiegelnden Spiegel einen simplen Realitätsbegriff aufzulösen und uns die Möglichkeit an die Hand zu geben vermag, auch das als Realität zu beschreiben, was als Traum, als Fiktion unseren Sinnen präsent ist und folglich mit gleichem Recht einen Realitätsanspruch formuliert. Alle Unterschiede zwischen Urbild und Abbild, Wirklichkeit und Traum, Realität und Fiktion relativieren sich, sobald wir in die Spiegel sehen, die keine Realität mehr außerhalb des Spiegels reflektieren, sondern einen Reflex im Reflex, Literatur in der Literatur. Sind denn die Vorstellungen, die wir uns von der Welt machen, nicht ebenso sehr von Realitäten bestimmt wie von Fiktionen, die von anderen für uns mit guten wie mit bösen Absichten erstellt werden oder die wir für uns selbst herstellen? Wir werden sehen, welche Bedeutung diese Deutung der sich spiegelnden Spiegel für André Bretons Erfolgstext Nadja besitzt.

Bretons Nadja ist ein experimenteller avantgardistischer Text, der gattungstheoretisch nur sehr schwer einzuordnen ist. Der 1928 erstmals erschienene Band trägt sicherlich die Züge einer Erzählung, ist zugleich aber - wie Sie schon sahen - passagenweise eine Abhandlung, ein Traktat, ja bisweilen ein Manifest, dann wieder Reportage, Erlebnisbericht, autobiographische Skizze, dazu noch aufgrund der eingearbeiteten Photographien und anderer Dokumente eine Art Bild-Text, ein Ikonotext in einem starken Sinne. In diesem Prosaband kommt ein Ich zu Wort, das alle Züge von André Breton trägt und auch in André Bretons Namen auftritt.

In der Sekundärliteratur bis hin zur Pléiade-Ausgabe wird dieses Ich mit André Breton als textexternem Autor kurzgeschlossen und identifiziert; doch kann ich vor einer solch simplistischen Identifikation nur warnen. Man setzt nicht ungestraft textexternen Autor in eins mit den von ihm geschaffenen Figuren, auch wenn dies stellenweise Sinn machen mag: $\mathrm{Zu}$ hoch ist der Verlust an Kom- 
plexität und die Nicht-Wahrnehmung jener Spiegelungseffekte, über die uns der Text selbst in der oben angeführten Passage erhellt. Denn der Prosatext Nadja pendelt ständig zwischen den verschiedensten Gattungen, aber auch zwischen der Gestaltung von Traumberichten und Wirklichkeitsdokumenten, zwischen fiktionalen Erzähltechniken und essayistischen Argumentationsmodi. Wie soll man einen solchen Experimentaltext benennen?

Der französische Literaturtheoretiker Gérard Genette hat vor einigen Jahren ${ }^{8}$ eine grundlegende Unterscheidung aufgemacht zwischen „diction“ und „fiction“, also zwischen fiktionalen und diktionalen Texten, wobei man letztere - um des lieben Friedens mit unseren angelsächsischen Freunden und der pragmatischen Vereinfachung willen - auch im englischsprachigen Sinne als nicht-fiktionale oder „non-fictional texts“ bezeichnen könnte. Was aber ist mit jenen Texten, die nicht eindeutig dem einen oder dem anderen Bereich zuzuordnen sind, die schlimmer noch - zwischen beiden Bereichen hin- und herpendeln, ständig zwischen Fiktion und Diktion oszillieren? Ich habe vor einigen Jahren den Begriff der „Friktion“ dafür vorgeschlagen. ${ }^{9}$ Und dieser Begriff trifft, so scheint mir, recht präzise die eigentliche, grundsätzliche Verfahrensweise von Bretons Nadja. Er pendelt ständig zwischen Reportage und literarischer Erzählung, Abhandlung und Traumbericht, dokumentarischen Photographien und künstlerisch-ikonischen Darstellungsformen, so dass übrigens ganz nebenbei auch eine grundlegende intermediale Dimension in diesen Text eingeht.

Doch nicht nur das: Der Text pendelt auch programmatisch zwischen Literatur und deren existentieller Umsetzung, folglich zwischen Kunst und Leben, und auch hier werden - wie wir gleich sehen werden - die Grenzen zwischen beiden verwischt. Der letzte Abschnitt des ersten Teils präzisiert die Ziele, die mit diesem in vielerlei Hinsicht experimentellen Text verfolgt werden, aus der Sichtweise des Ich wie folgt:

Ich hoffe aber in jedem Falle, dass die Präsentation einer Serie von Befolgungen dieser Anordnung und jener, die ihr noch folgen wird, geeignet sein wird, bestimmte Menschen auf die Straße zu treiben, nachdem ihnen zu Bewusstsein gebracht wurde, zwar nicht das Nichts, aber zumindest das schwerwiegende Ungenügen scheinbar genauen Kalküls für sie selbst zu begreifen sowie jeglicher Handlung, welche eine stetige und wo möglich absichtsvolle Anwendung erforderlich macht. ${ }^{10}$

8 Vgl. Genette, Gérard: Fiction et diction. Paris: Editions du Seuil 1991.

9 Vgl. hierzu Ette, Ottmar: Roland Barthes. Eine intellektuelle Biographie. Dritte, unveränderte Auflage. Berlin: Edition Suhrkamp 2012, S. 308-312.

10 Breton, André: Nadja, S. 49. 
Mit diesen Zeilen kündigt sich im Grunde bereits eine Denk- und Bewegungsfigur an, die wir später im Zweiten Manifest des Surrealismus aus dem Jahr 1930 wiederfinden werden. Sie besagt, dass der surrealistischste Akt jener ist, auf die Straße hinunterzugehen und ungezielt und zufällig auf die Leute zu schießen, die man gerade erwischen kann. Das „précipiter dans la rue“ ist im obigen Zitat freilich nicht so gemeint. Hier ist - auch in Hinblick auf das Kommende - die Straße Ort der Begegnung, des unkalkulierbaren Zufalls, jener Thematik, die in Baudelaires Gedicht $A$ une passante schon im Kontext einer Stadtlandschaft der Romantik so wunderschön entfaltet worden war.

Das Motiv der Zufallsbegegnung, das im Übrigen von Erich Köhler auch in die Dialektik von Zufall, Möglichkeit und Notwendigkeit einbezogen worden ist, ${ }^{11}$ reicht freilich nicht aus, um den surrealistischen Anspruch an die eigene Lebensgestaltung zu erfüllen. Denn in den obigen Überlegungen geht es ganz wesentlich darum, die Grenzen strenger Logik, des Kalküls, des Rationalismus zugunsten einer Erfahrung eines Jenseits dieser Grenzen liegenden Bereichs zu sprengen. Auch in diesem Kontext erweist sich der Surrealismus als eine auf konkreter Erfahrung und direktem Erleben beruhende Experimentalanordnung, als gezielter Versuch, die Grenze zwischen Literatur und Realität, Kunst und Leben zu durchbrechen, um Lebensprozess und Kunstprozess ineinander fließen zu lassen. Das literarisch dokumentierte Ergebnis dieser Anordnung ist der friktionale Text Nadja selbst.

Mit Nadja, die sich ihren Namen in Anklang an das russische Wort für Hoffnung, „Nadjeschda“, gegeben und damit eben dieser Erwartungshaltung des plötzlich Eintreffenden und Ersehnten schon in ihrem Namen Ausdruck gegeben hat, tritt uns die Figur der schönen Unbekannten entgegen. Dabei erscheint sie in der Variante einer letztlich an nichts zurückzubindenden, die Grenzen der Logik durchbrechenden Frauenfigur, welche damit selbstverständlich eine Reihe weiblicher Stereotypen und Topoi entfaltet. Es fällt nicht schwer, den männlichen Blick auf die Frau in seinen Grundlinien zu erkennen: Denn natürlich ist Nadja schön, spontan, sie reagiert unvorhersehbar und emotional, sie hat noch den leichten Dunst einer Frau, die ihren Körper zu nutzen weiß. Im Übrigen besitzt sie, wie leicht angedeutet wird, auch den Hang zur Prostitution, um ihren eigenen Lebensunterhalt zu sichern, um allein und unabhängig im Hotel leben zu können. Doch zugleich entspricht sie auch einem anderen Bild einer Frau, die frei durch die Straßen geht, ungezwungen mit all jenen spricht, die sie interessieren, selbst die Initiative ergreift und einen selbstbestimmten Eindruck vermittelt.

11 Vgl. Köhler, Erich: Der literarische Zufall, das Mögliche und die Notwendigkeit. München: Fink 1973. 
Übrigens soll es Nadja in Bretons Leben wirklich gegeben haben: Dies beweisen beispielsweise einige Briefe von ihr an Breton, Briefe, denen der französische Schriftsteller vieles entnommen habe. Zwischen den Spiegeln, die sich wechselseitig reflektieren, spielt die Dokumentation eine wichtige Rolle, gleichviel, ob es die einer außersprachlichen Wirklichkeit oder einer gelungenen Fiktion ist. Das ganze Geschehen ist wie in einer Reportage präzise datiert und auf genaue Szenarien aufgeteilt, welche beschrieben und zusätzlich durch Photographien dokumentiert werden. Und trotz alledem: Es ist ein Spiel der Spiegel.

Nicht umsonst spricht der Erzähler von einer „entrée en scène“ seiner Nadja: Es ist eine literarische Inszenierung und kein expositorischer Bericht, keine reine Reportage, die allein diktionalen und keinerlei fiktionalen Charakter besäße. An derlei Stellen lässt sich das Friktionale des Textes, das sein Spiel mit der Leserschaft umfasst, ganz unzweideutig nachzeichnen und transparent nachvollziehen.

Schauen wir uns diese Inszenierung einmal näher an! Das Ich ist gerade mit dem freien, ungezwungenen Flanieren beschäftigt, mitten in Paris. Ich gebe die literarische Szenerie leicht gekürzt wieder:

\begin{abstract}
Ohne es zu wollen beobachtete ich Gesichter, Aufmachungen, Allüren. Aber was denn, das wären noch nicht diejenigen, die man bereit dazu fände, die Revolution zu machen. Ich überquerte gerade die Kreuzung, deren Namen ich vergesse oder nicht weiß, da, vor einer Kirche, urplötzlich und während sie etwa noch zehn Schritte von mir entfernt ist, sehe ich in entgegengesetzter Richtung eine junge, sehr ärmlich gekleidete Frau, die mich ebenfalls sieht oder bereits gesehen hat. Sie läuft mit erhobenem Kopf, im Gegensatz zu allen anderen Passanten. So zerbrechlich wirkt sie, kaum laufend. Ein unmerkliches Lächeln irrt vielleicht über ihr Gesicht. [...] Noch nie hatte ich solche Augen gesehen. Ohne jedes Zögern richte ich das Wort an die Unbekannte, wobei ich, das gebe ich zu, das Übelste erwartete. Sie lächelte, freilich sehr mysteriös, und so, als wüsste sie Bescheid, auch wenn ich damals nichts davon glauben konnte. ${ }^{12}$
\end{abstract}

Wir schreiben den 4. Oktober 1926. Die Datierungen geben dem Text eine Art Tagebuchform und verstärken damit den Aspekt des Authentischen und mehr noch des Erlebten und Gelebten. Die Leserinnen und Leser stehen mittendrin im Geschehen, so als spräche der Erzähler direkt zu ihnen: Präsentische Ausdrucksformen versichern sich ständig des Kontakts. Denn es ist die Dimension des Erlebten und Gelebten, welche tatsächlich ausschlaggebend für die in Nadja entwickelte Textsorte ist. Sie unterstreicht, dass es sich hier um eine wirkliche Begegnung handelt, um eine Begegnung der zufälligen Art: Das literarische

12 Breton, André: Nadja, S. 51-53. 
Motiv der Zufallsbegegnung in der Stadt mit einer schönen Unbekannten, zunächst ganz im Stile von Baudelaires A une passante. Doch Nadja scheint von vorneherein Bescheid zu wissen, handelt „en connaissance de cause“ und lächelt rätselhaft wie eine Sphinx den Ich-Erzähler an. Das (literarische) Experiment kann beginnen.

Die Ausgangssituation des männlichen Ich ist die des Flaneurs, der aufmerksam alles betrachtend die Straßen hinauf- und hinuntergeht und nach Interessantem Ausschau hält. Er steht vor der Buchhandlung von L'Humanité, dem Buchladen der Kommunistischen Partei Frankreichs, der ebenfalls durch eine Photographie im Band dokumentiert ist. Denn die Photographien unterstützen und stärken die friktionale Dimension, sie befestigen das Dokumentarische, das dem Band die existentielle Verankerung vermittelt. Der Blick des Ich-Erzählers in die Gesichter der vorbeiströmenden Menschen - es ist derselbe Blick, den auch Nadja nach eigener Aussage auf die Menschen in der Metro wirft - verrät dem Ich, das die erwünschte, die erträumte Revolution noch weit entfernt ist. Frankreich scheint für die Revolution noch nicht reif zu sein. Oder ist es vielleicht dieselbe Fehleinschätzung, die im Zürich der Dadaisten Lenin unterlief, der die Revolution etwa in Deutschland, nicht aber in seinem eigenen Russland heraufziehen sah?

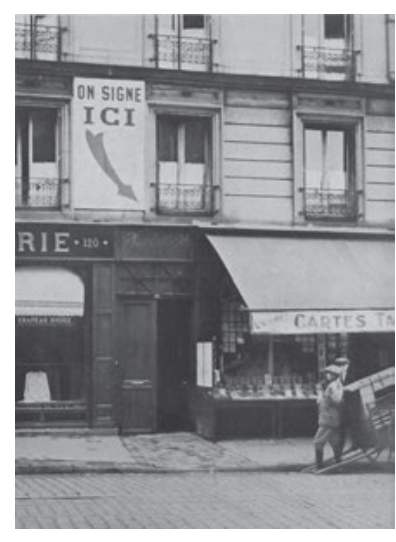

Abb. 83a: Die Buchhandlung von L'Humanité, Abbildung in Bretons Nadja, 1928.

Zweifellos ist in dieser Zusammenstellung des Publikationsorgans der Kommunistischen Partei Frankreichs und der Rede von der Revolution die politische Dimension unmittelbar angesprochen. Doch denke ich, dass sich gerade auch in der nachfolgenden Szenerie zeigt, inwiefern der Ich-Erzähler eine umfassende Revolution im Auge hat, welche sich nicht bloß auf die Durchsetzung der politischen Ziele des Kommunismus beschränkt. Gleichzeitig wird in der Folge deutlich, dass André Breton, der seit 1927 Parteimitglied ist, den Text in keiner Weise als Propa- 
gandamaterial verwendet oder auch nur versuchen würde, der Kommunistischen Partei oder dem marxistischen Denken eine schöne Rolle zuzuschanzen. Nichts von alledem - und eben dies machte viele Menschen nachdenklich! Mir scheint daher - ähnlich wie der Kommentatorin der Pléiade-Ausgabe von Nadja -, dass hier entscheidend die Unabhängigkeit Bretons und des Surrealismus gegenüber der Kommunistischen Partei, die ja nicht ausgeschlossen wird, sondern im Text präsent ist, betont und hervorgehoben werden soll.

In jedem Falle kommt es zum Treffen mit einem rätselhaft, ,sphinxartig“ lächelnden, wenn auch ärmlich gekleideten Mädchen mit unergründlichen Augen. Dieses Lächeln und auch andere Elemente verleihen der Zufallsbegegnung etwas Schicksalhaftes, etwas Erwartetes, etwas geradezu Selbstverständliches und Notwendiges. Zum Vergleich könnte man auf eine Passage des ersten Teils verweisen, wo das Erzähler-Ich von einer jungen Frau berichtet, die ihn, den im Automobil Vorüberfahrenden, angeschaut hatte, er aber leider nicht ausgestiegen war, was er hätte tun sollen. Bei der Begegnung mit Nadja geht er hingegen auf die erhobenen Hauptes und nicht gesenkten Blicks flanierende, offenkundig ziellos durch Paris spazierende Frau zu und ergreift die Gelegenheit beim Schopf.

So lernt der Ich-Erzähler Nadja kennen. Ein erotischer Konnex oder gar eine sexuelle Konnotation scheinen über die Tatsache eines Treffens zwischen einem Mann und einer jungen Frau hinaus nicht gegeben. Zwar wird das Thema einer erotischen Beziehung mehrfach kurz gestreift, zumal auch Nadja am Ende des ersten Treffens darüber erstaunt ist, dass der Ich-Erzähler eine Frau hat. Doch ist für das Ich die junge Frau nicht Spielpartnerin in einer Geschlechterbeziehung der erotischen Art, sondern eine Art Medium, mit Hilfe dessen neue Erfahrungen gemacht werden können. Dass das Ich ganz nebenbei auch der Eingangsfrage nach der eigenen Identität auf die Spur kommen kann, ist mit der sich entwickelnden Beziehung ebenso verknüpft wie jene Dimension einer fundamentalen Revolution, die unmittelbar vor der plötzlichen Erscheinung Nadjas aufgeleuchtet war.

Das Entscheidende Merkmal, das ihm an ihr auffällt, sind ihre Augen: Nie zuvor habe er solche Augen gesehen. Dabei handelt es sich durchaus nicht um ein Allerwelts-Kompliment, das man einer schönen jungen Dame in den Straßen von Paris machen könnte. Denn Nadjas Augen werden später auch in einer photographischen Montage wiederholt, als übereinander geschnittenes Augenpaar, das den Betrachter anblickt. Es sind Augen, wie er sie noch niemals sah; und sie werden in einem ersten Schritt einer kurzen Beschreibung unterzogen, welche die Beziehung dieser Augen zur Schminke und von dort zu Blanche Derval herstellt, jener französischen Schauspielerin, welche die Rolle von Solange innehatte und ebenfalls wenig geschminkt gewesen zu sein scheint. 

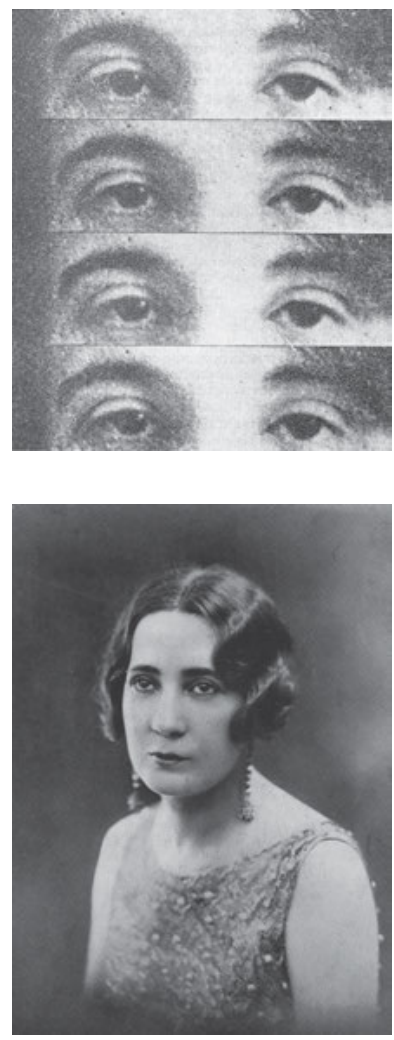

Abb. 83b: André Breton: Ses yeux de fougère (Nadjas Augen), photographische Montage aus Nadja, 1928.

Abb. 83c: Blanche Derval, Abbildung aus Nadja, 1928.

In der Tat ist das Element der Schminke symptomatisch: Denn nicht allein die aufgetragene Schminke, sondern auch die fast nicht vorhandene Schminke setzt ein Zeichen, dass entgegen der kosmetischen Normen des französischen Bürgertums dieses Mittel mittelmäßiger Schönheit kaum eingesetzt wurde und somit ein gleichsam direkter Zugang zur Natürlichkeit der Frau gegeben scheint. Gemäß einer alten, jahrtausendealten Topik können die Augen so wie in der mittelalterlichen oder frühneuzeitlichen Mystik zu den Fenstern der Seele werden. Die Schminke, der kunstvolle „maquillage“, ist in der literarischen Tradition oftmals mit der Rhetorik, einer Art ,kosmetisch“ aufgetragener Sprache verknüpft, so dass von Beginn an eine Art Direktheit, sozusagen eine Rhetorik der Nicht-Rhetorik, signalisiert wird, welche zum im Text behaupteten faktischen Charakter und damit letztlich zur friktionalen Tendenz dieses gesamten Experimentaltextes hervorragend passt und beiträgt.

Im Übrigen kann unsere hübsche Nadja ihren inszenierten Auftritt, ihr äußeres Erscheinungsbild und ihren allgemeinen Habitus sehr stark verändern, taucht sie doch bereits am nächsten Tag beim Wiedersehen nicht mehr in ärm- 
licher Kleidung auf, wie dies beim Zufallstreffen geschah, sondern in einer sehr herausgeputzten Robe, so dass der Erzähler auch diese Besonderheit betont. Dergestalt kommt denn auch bei dieser zweiten Begegnung die Konversation eher stockend in Gang. Beim ersten Treffen jedoch hatte sich sehr leicht, geradezu natürlich, eine gemeinsame Gesprächsebene ergeben. Das Ich erwartete zwar die konventionalisierte Zurückweisung durch die junge Frau, aber eine solche erfolgte nicht: Die Unbekannte öffnete sich vielmehr gegenüber dem sie ansprechenden Unbekannten, womit Nadja gleich zu Beginn eine erste gesellschaftliche Konvention der bürgerlichen Gesellschaft übersprang.

Auch in der Folge werden die gesellschaftlichen Normen - wenn auch nicht im erotischen Bereich - gleich mehrfach übersprungen, was aus heutiger Sicht freilich einer bestimmten Rekonstruktionsarbeit bedarf, da vieles von dem, was der Text uns vorführt, auf der Ebene des Alltagsverhaltens und der sozialen Umgangsformen heutzutage selbstverständlich geworden ist. Man könnte sehr wohl mit guten Gründen behaupten, dass sich surrealistische Vorstellungen - oder genauer: Vorstellungen, die auch von Surrealisten für sich reklamiert wurden - insgesamt in der Gesellschaft durchgesetzt haben. So ist Nadja als Frau den Umgangsformen ihrer Zeit voraus.

Im gleichen Atemzug sind von Beginn an das nicht zu Fassende, das Unkonventionelle und vor allem das Mysteriöse bei Nadja sichtbar und spürbar. Es gibt eine Vielzahl von Ambivalenzen und (im Iser'schen Sinne) von Unbestimmtheitsstellen, die übrigens auf der konkreten Textebene nicht zuletzt durch die vielen „peut-être“, durch das viele „vielleicht“, zum Ausdruck gebracht werden. Die grundsätzliche Atmosphäre ist die einer großen Offenheit für die Zukunft: Weder das Ich noch die Leserschaft wissen, wie sich die Geschichte weiterentwickeln wird. Aufschlussreich - und durchaus literarisch unterfüttert - aber ist die Tatsache des Sich-Erkennens selbst inmitten des Getriebes und Gewimmels der Großstadt, einer Art Anagnorisis, einem Wiedererkennen, dessen Gründe oder Vorgeschichte niemals richtig erhellt werden. Erkenntnis und Selbsterkenntnis sind freilich Attribute, welche spätestens seit der Romantik topisch an die Liebesbeziehungen geknüpft sind: In der Liebe erkennen wir uns selbst im Anderen und eröffnen uns eine weitere Form von Erleben und Erkennen. ${ }^{13}$

Nadja ist sehr wohl in der Lage, sich wie eine „voyante“ durch die Zeit zu bewegen. Sie kann zum Beispiel bei einem Besuch in einem Restaurant vorher-

13 Vgl. hierzu die Vorlesung über Liebe und Lektüre in Ette, Ottmar: LiebeLesen. Potsdamer Vorlesungen über ein großes Gefühl und dessen Aneignung. Berlin - Boston: Verlag Walter de Gruyter 2020, S. 33-59. 
sagen, dass sich in einer Minute ein Zimmer erhellen wird und welche Farbe die Gardine dieses Zimmers besitzt. Sie vermag aber auch, Dinge der Vergangenheit zu erspüren, so dass sie in einem Innenhof einmal auf den Gedanken kommt, dass in jenem Polizeikommissariat der Ich-Erzähler (und vielleicht auch sie selbst?) einmal eingesperrt gewesen waren. Dies wird nicht rational erläutert oder erhellt, sondern trägt zu der etwas mysteriösen Atmosphäre bei, welche das gesamte Treffen trotz aller Versuche umgibt, den Tatsachenbericht sowie das Dokumentarische in den Vordergrund zu rücken.

Am Ende des ersten Treffens kommt es nicht etwa - wie ein ,klassischer` Leser hätte annehmen können - zu einem Schäferstündchen oder einer Liebesnacht, welche die Zufallsbegegnung hätte krönen können, sondern zu einem bedeutungsvollen ersten Abschied. Dabei stellt der Ich-Erzähler der jungen Frau jene Frage, die er sich gleich im ersten Satz des Textes selbst gestellt hatte: die Frage nach der Identität, nach dem „Wer bin ich?“, nach dem „Wer bist Du?“:

Als ich bereits weggehen will, möchte ich ihr eine Frage stellen, die alle anderen in sich trägt, eine Frage, die wohl allein ich ihr stellen kann, die aber zumindest einmal eine Antwort auf ihrer Höhe gefunden hat: „Wer sind Sie?“, und sie, ohne zu zögern: „Ich bin die umherirrende Seele.“ Wir kamen darin überein, uns am nächsten Tag in der Bar wiederzusehen, die auf der Ecke zwischen Rue Lafayette und Faubourg Poissonnière liegt. Sie würde gerne ein oder zwei Bücher von mir lesen und legt umso größeren Wert darauf, als ich ernsthaft das Interesse in Frage stelle, das sie daran finden kann. Das Leben ist anders als das, was man schreibt. Sie hält mich noch einige Augenblicke zurück, um mir zu sagen, was an mir sie berührt. In meinem Denken, in meiner Sprache, in meiner ganzen Art zu sein ist es, und dies scheint eines der Komplimente zu sein, für welches ich in meinem Leben am empfänglichsten war, die Einfachheit. ${ }^{14}$

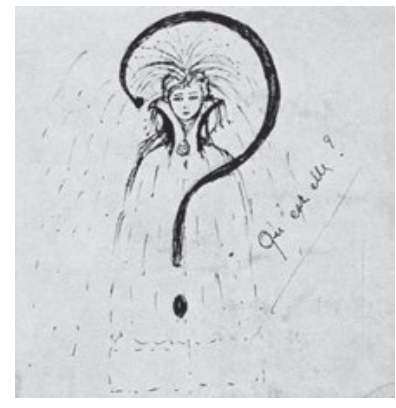

Abb. 83d: Léona Delcourt: Qui est elle? (Wer ist sie?), 1926, Zeichnung aus Najda, 1928. 
In dieser Passage wird jene große Frage gestellt, die alle anderen resümiere und in sich enthalte. So scheint die Identität, vielleicht mehr noch die Suche nach der Identität, im Zentrum dieses Buches über eine Zufallsbegegnung mit einer jungen unbekannten Frau zu stehen. In der Reiseliteratur würde man angesichts dieser Konstellation vom Rebecca-Motiv sprechen, das sich so häufig in reiseliterarischen Texten männlicher Autoren findet. ${ }^{15}$ Dieses Motiv resümiert in gewisser Weise die gesamte Reise des männlichen Subjekts, insofern es nun in der eigentlich unbekannten schönen Frau wie in einer Mise en abyme, gleichsam in einer fraktalen Verdichtung, das ganze Land aufgeschlossen findet, welches das Ich zu bereisen plant. Man könnte dieses reiseliterarische Moment durchaus an vielen Stellen von André Bretons Nadja wiederfinden, bildet der gesamte Experimentaltext doch eine Erzählstruktur, welche einer Reise durch ein bekanntes und zugleich unbekanntes Land überaus ähnelt.

Die Grundstruktur der Suche prägt den gesamten Prosatext, prägt die Bewegungen der Protagonisten durch die Straßen von Paris, dessen Orte und Lokalitäten sehr genau beschrieben werden. Der nächste Treffpunkt ist die Bar mit dem schönen, für einen reiseliterarischen Text höchst angemessenen Namen La Nouvelle France. Aber derartige Orte und Cafés sind lediglich die Schnittstellen, in denen sich die isolierten vektoriellen Linien der individuellen Bewegungen überkreuzen, einige Zeit beieinander verharren und sich danach wieder auseinander bewegen und aus den Augen verlieren. Die Frage nach der kollektiven Identität, etwa nach jener auf einer nationalen Ebene, wird in Bretons Nadja nicht gestellt, es sei denn, es wäre die Frage nach der Menschheit insgesamt oder dem Menschen überhaupt. Doch bildet die Suche nach der individuellen Identität eine Herausforderung, die von der anonymen und doch namhaft zu machenden Stadtlandschaft ständig dem in dieser Landschaft flanierenden oder umherirrenden Individuum entgegengebracht wird: Wer bist Du? Die schwankenden, oszillierenden Bewegungen der Protagonisten geben hierauf keine Antwort, sie zeigen eher als hermeneutische Verstehens-Bewegungen diese Unsicherheit und mehr noch die große Offenheit bei der Beantwortung dieser Frage auf. Die Bewegungsfiguren aller Handelnden und Suchenden sind von unterschiedlichen Sprüngen gekennzeichnet und lassen dergestalt eine vektorielle Figuration erkennen, welche nicht die eines klaren Erkenntnisgewinns, sondern einer unveränderlichen Suche ist. Doch auf welcher Suche befinden sich diese ruhelosen Figuren in der Stadtlandschaft von Paris?

15 Vgl. die Vorlesungen zur Reiseliteratur in Ette, Ottmar: ReiseSchreiben. Potsdamer Vorlesungen zur Reiseliteratur. Berlin - Boston: Walter de Gruyter 2020, S. 187. 


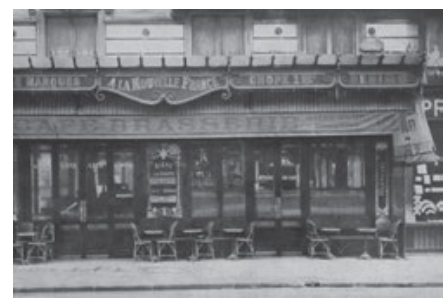

Abb. 83e: Fotografie der Bar „La Nouvelle France“ aus Nadja, 1928.

Nadja will die Bücher des Ich, das sich als Verfasser von Büchern zu erkennen gegeben hatte, lesen. Und am nächsten Tag wird ihr das Ich auch einige eigene Bücher mitbringen, darunter Les pas perdus und das Manifeste du Surréalisme. Sie sehen, wie eng Breton seine Erzählerfigur an seinen eigenen Biographemen ausgerichtet hat, um jenen friktionalen Effekt zu erzielen, der seinen gesamten Experimentaltext charakterisiert. Denn mit Hilfe dieses im Übrigen gar nicht so seltenen Verfahrens wird das textinterne Erzähler-Ich ganz direkt mit André Breton, dem textexternen Autor, kurzgeschlossen.

Wir bewegen uns übrigens noch in einer Epoche, in der die Bücher, wollte man sie lesen, Bogen für Bogen aufgeschnitten werden mussten, so dass sich der Ich-Erzähler auch kurze Zeit später Kenntnis davon verschaffen kann, wieviel und was Nadja in den Büchern, die er ihr mitbrachte, tatsächlich gelesen hat. Immerhin trägt sie bei einem weiteren zufälligen Treffen geradezu emblematisch auf der Straße Les pas perdus in der Hand, was sie als authentische Leserin von André Breton zu erkennen gibt. Viel hat sie freilich nicht gelesen, aber der Text hatte uns ja vor den Büchern gewarnt in einem Satz, den Breton wohl erst ganz am Ende seinem Buch Nadja auf die Reise in die Öffentlichkeit mitgab: „Das Leben ist anders als das, was man schreibt.“ Dieser Satz, der das Verhältnis von Literatur und Leben charakterisiert, ist schillernd und betrifft einen zentralen Anspruch des Surrealismus, Kunst, Literatur und Leben miteinander zusammenzuführen.

Mit Hilfe dieses kleinen, später hinzugefügten Satzes wird zum einen eine klare Grenz- und Trennlinie zwischen dem, was man sonst so schreibe, und dem Leben gezogen, und zum anderen gerade jene Trennlinie wieder aufgehoben oder kassiert, da im vorliegenden Text diese Grenze nicht respektiert wird. Denn die Bücher werden ja zu einem Teil des Lebens der Protagonisten, haben ihre Bedeutung im Lebensvollzug der handelnden Personen im Buch. Wir könnten dies anders, zugespitzter formulieren: Das Buch Nadja behauptet in gewisser Weise, kein Buch zu sein, nicht geschrieben worden zu sein, sondern das Leben selbst darzustellen, zu vermitteln, zu kommunizieren, zu sein.

Genau auf diesem Punkt liegt der eigentliche Impetus des Buches und eine wesentliche Dimension der friktionalen Präsentation und literarischen Charak- 
teristika von Bretons Nadja. Denn es geht in diesem Text um die Erfahrung des Gelebten, Unmittelbaren, des nicht artifiziell Arrangierten, sondern des Zugestoßenen, des Leb-Haften, des unmittelbar Erlebten. Wir stoßen in diesem Buch auf ein Eindringen des Lebens in die Kunst, oder anders: Das Leben verwandelt sich in Kunst, ohne doch als Leben beendet zu sein; denn die Geschichte, die uns mit literarischen und photographischen Mitteln erzählt wird, bleibt offen. Friktional ist der Breton'sche Text auch in dieser Hinsicht, dass er zwischen Leben und Kunst, existenzieller Lebensform und Literatur keine eindeutige Trennlinie oder Mauer errichtet. Dazu passt just an dieser Stelle die erneute Bemerkung, dass sich das Ich einer großen Simplizität, einer Einfachheit erfreue, jener Einfachheit also, die für die Leserschaft sicherstellt, dass die Geschichte, die hier niedergeschrieben wurde, nicht mit der Schminke, nicht mit dem „fard“ der Rhetorik ausgeschmückt und verunstaltet, verstellt worden ist. Natürlich ist das selbst wiederum nichts anderes als eine andere Form von Rhetorik, von Literarizität. Aber man könnte mit guten Gründen ein wenig barthesianisch von einem „degré zéro“ literarischer Rhetorik in diesem friktionalen Text André Bretons sprechen.

Eine mit dieser Verknüpfung von Leben und Literatur zusammenhängende, aber sicherlich auch unabhängig davon zu betrachtende Dimension ist in Nadja jene der Intermedialität und Ikonotextualität. Denn eine Vielzahl von Photographien, aber auch von Reproduktionen von Kunstwerken, „objets trouvés“ und anderer Dinge begleiten den Text und verwandeln ihn selbst in ein kleines Kunstwerk. Mit Blick auf die Photographien kann man nicht davon sprechen, dass sie den Text ,illustrieren' oder dass der literarische Text sie umgekehrt ,illustriert‘. Sicherlich gibt es eine gewisse Illustrationsfunktion, zumal die Photographien immer genau dann in den Text eingefügt sind, wenn sie im Schrifttext angesprochen werden. Diese direkte Beziehung wird noch dadurch verstärkt, dass unter den Bildern oder Photographien jeweils die diesbezügliche Textpassage erscheint. Allerdings gibt es eine zweite Funktion, nämlich die der Dokumentation. Dies müssen wir im Auge behalten!

Eine Photographie, so Roland Barthes in seinem bereits angeführten letzten zu Lebzeiten veröffentlichten Buch, ${ }^{16}$ sagt nicht zuletzt, dass all dies einmal gewesen ist: „ça a été.“ Es wird nie wieder so sein - und damit schreibt sich der Tod in die Licht-Schrift ein, in das Schreiben der Photo-Graphie. Unerbittlich vergehende Zeit und höchstens aufgeschobener Tod werden $\mathrm{zu}$ ihrem Bestandteil, denn das Dokumentarische konserviert, bewahrt auf, hält fest, holt aus dem kontinuierlichen Fluss der Zeit heraus; aber gerade darum macht es museal, iso-

16 Vgl. hierzu Barthes, Roland: La Chambre claire. Note sur la photographie. Paris: Seuil 1980. 
liert, dekontextualisiert und tot. Die intermediale, bild-textliche Einbindung in den Text versucht in gewisser Weise, diesen Tötungsprozess zumindest zu relativieren, ihm die Schärfe zu nehmen.

Die ikonotextuelle, nicht-illustrierende Funktion der Photographien enthält aber auch eine dritte Funktion, nämlich diejenige, eine weitere eigene Geschichte in den Text einzubauen, indem sich zwischen den verschiedenen Bildern eigene Serien herstellen lassen. Nennen wir einige dieser Bilder-Serien: Da gibt es zum Beispiel die Stadtansichten von Paris, da gibt es jene Photographien von Frauen, die immer wieder in den Prosatext eingestreut sind, da gibt es Photographien von Männern wie Robert Desnos, Benjamin Péret oder André Breton selbst, die sozusagen eine surrealistische Künstlerlinie aufmachen, aber auch in einen eigenartigen Kontrast zu den Frauenbildnissen eintreten. Doch mehr noch: Da gibt es eine Serie von „objets trouvés“, die im Verlauf der Handlung eine gewisse Rolle spielen, aber eben auch als Photographien und Reproduktionen anwesend sind. Es erscheint eine Serie von Kunstwerken, die auf den surrealistischen Hintergrund verweisen und uns mit Bildern verschiedener Künstler konfrontieren; und da sind nicht zuletzt die flüchtigen, zum Teil aber auch sehr elaborierten Skizzen und Bilder, die uns Nadja höchstselbst hinterlassen hat und die von der Erzählerfigur in den Text einmontiert wurden.

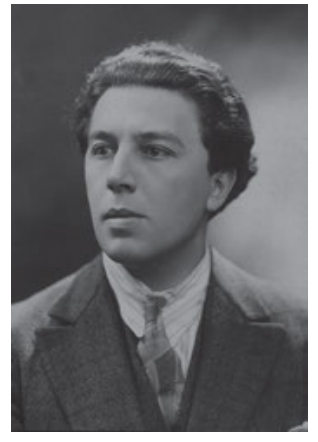

Abb. 83 f: Henri Manuel: André Breton um 1927, Photographie aus Nadja, 1928.

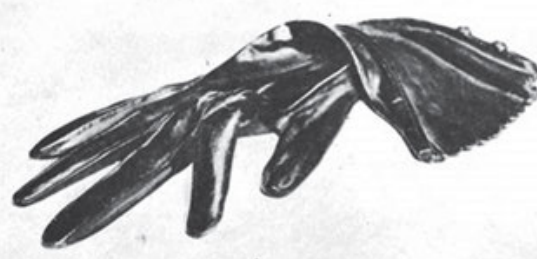

Abb. 83g: Frauenhandschuh aus Bronze, Abbildung aus Nadja, 1928. 


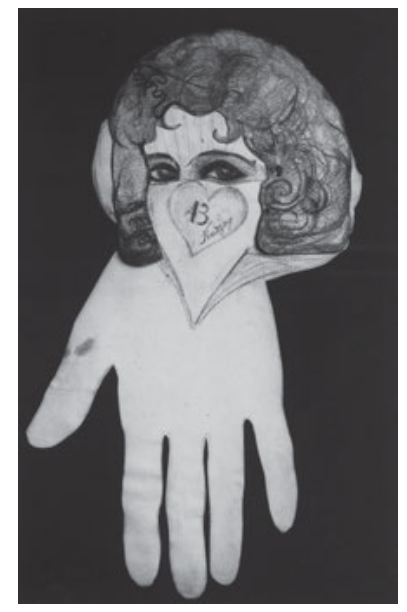

Abb. 83h: Léona Delcourt: De manière à pouvoir varier l'inclinaison de la tête, Collage und Zeichnung aus Nadja, 1928.

Die Montage ist ein Verfahren, das sowohl für den Schrifttext als auch für den Bildtext gilt und als ein beide Bereiche miteinander verbindendes künstlerischliterarisches Vorgehen verstanden werden kann. Bild und Text, Text und Bild verweisen wechselseitig aufeinander: Auf pointierte und höchst bewusste Weise ist Nadja ein Ikonotext, in welchem die schrifttextliche beziehungsweise skripturale Dimension nicht von der bildtextlichen abgehoben und getrennt werden kann. Damit werden die literarischen Darstellungsmodi von Breton mit jener künstlerischen Ausdrucksform verwoben, mit der er sich zeitlebens sehr intensiv beschäftigte und der einige seiner wichtigsten Essays gelten, dem Gemälde. Allein aus Zeitgründen müssen wir an dieser Stelle darauf verzichten, die Beziehung Bretons zur Malerei näher herauszuarbeiten, eine Beziehung, die stets auch die Kunst als Teil des Lebens, als Teil der Existenz und mehr noch als Teil des Gelebten wie Erlebten verstand und in das eigene Schaffen Bretons einbezog.

Die Kunstäußerungen von Nadja sind im Lichte ihres späteren, im Buch nur wenig verfolgten Lebensweges mit einem weiteren Phänomen gekoppelt, das für die Surrealisten von größter Bedeutung war: dem Wahnsinn. Denn bevor die Geschichte Nadjas im letzten Teil des Bandes wieder völlig zurücktritt und einer anderen, autobiographisch fundierten, nicht unproblematischen und ephemeren Liebesgeschichte Platz macht, welche gleichsam die Kontinuität des Lebens andeutet, erfahren wir, dass Monate, nachdem sich der Ich-Erzähler und Nadja nichts mehr zu sagen hatten, die junge Frau in ein Irrenhaus eingewiesen wurde. Sie hatte offenkundig in ihrem Hotel einige ,Aufführungen' gemacht, welche Polizei und Ärzte dazu bewogen, sie aus der Gesellschaft - wie man so schön doppeldeutig sagt - zu entfernen. Nadja ist, so hört zumindest der Erzähler, verrückt geworden und in der Psychiatrie gelandet. 
Diese Information dient dem Ich-Erzähler als Sprungbrett, allerlei grundlegende (durchaus wohlbegründete) Zweifel an der zeitgenössischen Psychiatrie und, aus kulturkritischer Warte, an der bürgerlichen Gesellschaft vorzubringen, die derartige Ausschlussverfahren zulasse und die gesellschaftliche Exklusion durch Inklusion im buchstäblichen Sinne zu verantworten habe. André Breton war auf Grund seiner psychologisch-psychiatrischen Ausbildung ein durchaus interessanter Fachmann und Vertrauensmann; und so nutzte er auch diesen Teil der Geschichte wahrlich aus, um - wie man sagen könnte - über die Konzeption der Psychiatrie seiner Zeit kritisch herzuziehen. Beziehungen zur wissenschaftlich begründeten Auffassung der Psychoanalyse Freuds, der zufolge der Künstler - und natürlich auch die Künstlerin - ein Neurotiker oder eine Neurotikerin sei, kommen uns hier in den Sinn. Breton war sich der Schlagkraft dieser Überlegungen Sigmund Freuds sehr wohl bewusst.

Zweifellos weisen sie auf die hauptsächliche Zielrichtung hin, die Breton in seiner Kritik an der Psychiatrie interessiert. Am Beispiel von Jacques Vaché hatte Breton bereits die Verbindung zwischen Künstlertum und Wahnsinn wahrgenommen und diese ebenso die Gesellschaft wie die Rolle der Kunst beleuchtende Relation stets in seine eigenen Überlegungen und Kunsttheorien miteinbezogen. Ich möchte Ihnen daher den gesellschaftskritischen Teil seiner Angriffe nicht vorenthalten; denn diese werfen zugleich ein Licht auf die Vieldimensionalität der Revolution, die André Breton sich zum Ziel gesetzt hatte, wie auf mögliche Folgen, die das Interesse an Grenzbereichen, an Grenzbezirken des Lebens und der Existenz schließlich auch bei anderen Künstlern auslösen konnte. Beschäftigen wir uns zunächst mit unserem abschließenden Zitat aus Bretons Nadja:

Nach meinem Dafürhalten sind alle Internierungen arbiträr. Ich sehe weiterhin nicht ein, warum man ein menschliches Wesen seiner Freiheit berauben sollte. Sie haben Sade eingesperrt; sie haben Nietzsche eingesperrt; sie haben Baudelaire eingesperrt. Die Vorgehensweise, die darin besteht, des nachts zu kommen und Sie zu überraschen, Ihnen die Zwangsjacke anzulegen oder Sie auf jede andere Art in den Griff zu bekommen, ist dem Vorgehen der Polizei gleich, das darin besteht, Ihnen einen Revolver in die Tasche zu schmuggeln. Ich weiß, dass ich für den Fall, dass ich verrückt und seit einigen Tagen interniert wäre, sofort von einem Ausgang profitieren würde, was mich in meinem Delirium kaltblütig einen von denen - und vorzugsweise den Mediziner - ermorden ließe, die mir in die Hände fielen. Gewonnen hätte ich damit zumindest, wie die um sich Schlagenden in einem Raum allein verwahrt zu werden. Und vielleicht würde man mich ja in Ruhe lassen. ${ }^{17}$

17 Breton, André Breton: Nadja, S. 117. 
Diese Passage hat es für die Zeitgenossen in der damaligen bürgerlichen Gesellschaft Frankreichs in sich. Die auf provozierende Art und Weise angeschnittene und zugleich in der Art einer Abhandlung und eines Erzähltextes behandelte Problematik der Inklusion von Wahnsinnigen in sogenannten Irrenhäusern stellt alle Internierungen und Freiheitsberaubungen durch Mediziner und deren Handlanger radikal in Frage. Breton stellt sich so der Logik von Wegsperren und Bestrafen, die Michel Foucault genauestens inspiziert hat, durchaus proklamatorisch und provokatorisch in den Weg. Zugleich klagt er an und verweist auf die Internierung von berühmten Männern, die auf ihren Gebieten zweifellos Außerordentliches geleistet haben und die von den Surrealisten zu wichtigen literarischen, philosophischen und künstlerischen Bezugspunkten gemacht wurden.

Schauen wir uns diese Bezugspunkte für den Surrealismus kurz einmal an! Da ist zum einen Charles Baudelaire, dessen große Themen für Bretons Nadja wichtig wurden: vom Motiv des Flaneurs bis hin zu dem der urbanen Zufallsbegegnung, die bestimmend für den narrativen Rahmen des Experimentaltextes wurden. Mit seiner Lyrik und seinen „Artifiziellen Paradiesen“ wurde er zu einem der wichtigen Vorläufer einer surrealistischen Konzeption von Kunst und Leben. Ferner finden wir Friedrich Nietzsche, der einst in Turin einem Pferd um den Hals fiel und in eine tiefe Nacht sank, aus der er nicht mehr erwachen sollte, bis zu seinem Lebensende ausgestellt von seiner eigenen Schwester; über die enorme Bedeutung seiner Philosophie für das 20. aber auch für das 21. Jahrhundert haben wir bereits gesprochen. Der wohl an Syphilis Erkrankte steht zugleich für eine Denkfigur ein, welche spätestens seit Hegel die philosophische Reflexion stets mit der Gefahr des Wahnsinnig-Werdens, des Falls in den Wahnsinn, verband. Und da ist zu guter Letzt der Marquis de Sade, der zum Inbegriff des Verbotenen, des Tabuisierten schlechthin wurde und den Schlüssel für die Darstellung jenes Bereiches in Händen zu halten schien, der eine andere Welt, die an ihre Grenzen stoßende Welt körperlicher, sexueller Erfahrung, beinhaltete. Ein Vierteljahrhundert nach dem Erscheinen von Nadja gelang Sade der Sprung aus dem Giftschränkchen der Bibliotheken vieler Schriftstellerinnen und Schriftsteller des 19. wie des 20. Jahrhunderts und von der einseitigen Pathologisierung in die Anerkennung als großer Schriftsteller, ja sogar bis in die Schulbücher des Unterrichts an Frankreichs Schulen. Auch bei diesem Prozess standen die Surrealisten Pate, was einmal mehr für ihre gewaltige Ausstrahlungskraft und zugleich für die Aktualität ihrer Vorstellungen spricht.

Mit diesen drei Schutzheiligen ausgestattet, also mit Sade, Baudelaire, Nietzsche - wie nicht einmal ein halbes Jahrhundert später Roland Barthes mit Sade, Fourier, Loyola - spielte das Ich in Bretons Text seinerseits die Möglichkeiten durch, selbst verrückt zu werden, wobei es hier als potentielle Lösung sehr wohl den kaltblütigen Mord miteinbezieht, den Truman Capote in seiner Reportage 
In Cold Blood darstellen sollte. In dieser gesellschaftskritischen Passage werden anklagend die Ausschlussmechanismen der Gesellschaft - die Wörter, die Polizei, die Ärzte, die Internierungen - aufs Korn genommen, vor allem aber die Psychiatrie und die Psychiater, welche diesen Ausschlussmechanismen eine wissenschaftliche Legitimation verschaffen.

Gegen derlei Ausgrenzungen, gegen derlei Freiheitsberaubungen wendet sich das Ich, das Künstler-Ich, mit aller Vehemenz, insofern sie letztlich die revolutionären Dimensionen menschlicher Existenz und menschlichen Erlebens ausschließen. Ich möchte im Folgenden zu einem der großen französischen Autoren und Kulturtheoretiker vorstoßen, die sich dieser ,dunklen' Seite ganz bewusst zuwandten, die Welt des Sexus erforschten, Tabuisierungen zu reflektieren und aufzuheben versuchten und zugleich bemüht waren, das Böse als ein Thema in der Literatur ebenso dauerhaft wie bewusst $\mathrm{zu}$ verankern. Ich spreche von Georges Bataille, einer der großen Figuren der französischen Literatur des zurückliegenden Jahrhunderts, dessen Denken weltweit von eminenter Einflusskraft war und längst nicht mehr tabuisiert werden kann. Die von ihm einst gegründete Zeitschrift Critique finden Sie übrigens auch in unserer Bibliothek. 